\title{
Focal (segmental) dyshidrosis in syringomyelia
}

Kazumasa Sudo, Naoto Fujiki, Sachiko Tsuji, Minoru Ajiki, Takuya Higashi, Masaaki Niino, Seiji Kikuchi, Fumio Moriwaka, Kunio Tashiro

\begin{abstract}
The features or mechanisms of dyshidrosis have not been sufficiently clarified. Neither has the difference between hyperhidrosis and hypohidrosis. To clarify the features and mechanisms of dyshidrosis (hyperhidrosis and hypohidrosis) in syringomyelia, the clinical features focusing on hidrosis of 30 patients with syringomyelia and Chiari malformation located from a syringomyelia database were prospectively analysed. The patients were classified into three groups: eight patients $(26.7 \%)$ had segmental hypohidrosis, 10 (33.3\%) had segmental hyperhidrosis, and $12(40.0 \%)$ had normohidrosis. We found that the Karnofsky functional status for the hyperhydrosis and normohidrosis groups were significantly higher than for the hypohidrosis group $(p=0.0012)$, with no significant differences between the hyperhidrosis and normohidrosis groups. The duration from the onset of syringomyelia to the current dyshidrosis was significantly longer in the hypohidrosis group than in the hyperhidrosis group $(p=0.0027)$. A significant correlation was identified between the duration from the onset of syringomyelia to the time at study and the performance score $(r=-0.599$, $p=0.0003)$. The results substantiate previous hypotheses that in its early stage syringomyelia causes segmental hyperactivity of the sympathetic preganglionic neurons, and hyperactivity of these gradually subsides as tissue damage progresses. Focal hyperhidrosis may be regarded as a hallmark of a relatively intact spinal cord, as well as normohidrosis.

(F Neurol Neurosurg Psychiatry 1999;67:106-108)
\end{abstract}

Keywords: syringomyelia; Chiari malformation; dyshidrosis; sympathetic preganglionic neuron

Syringomyelia is responsible for dyshidrosis as well as other disorders of the autonomic nervous system. ${ }^{1-4}$ Although the link between syringomyelia and focal dyshidrosis (hyperhidrosis and hypohidrosis) has been described, no adequate notice has been taken of the phenomenon, ${ }^{15-8}$ nor has its mechanism been properly explained. ${ }^{1-3}$ 9-11 Furthermore, no descriptions have been offered of any relation between hyperhidrosis and hypohidrosis.
Methods

PATIENTS AND METHODS

We have stored clinical data of a consecutive 34 patients $(0.28 \%)$ with MRI confirmed syringomyelia and Chiari malformation among the 11 967 outpatients who visited our neurology clinic from April 1989 to November 1996. Three quarters of the patients came without referral, and a quarter came with referral. Our outpatient clinic is not only a primary but also a secondary and tertiary centre for diagnosis and treatment of all neurological disorders. The case records of each patient showed that there had been no referral bias to our clinic as a consequence of our interest in dyshidrosis in syringomyelia. The protocol includes items for the autonomic nervous system as well as other systems. The data were obtained prospectively, with the intention of avoiding any predetermination bias, according to a protocol for examining patients with syringomyelia, which we ourselves designed. At the time of registration for this study, we obtained informed consent from patients to enter their information into our study database. Four of the 34 patients were dropped from the study because they refused to give us permission to employ clinical information about themselves for any clinical study; this left 30 patients. Twelve of these patients were operated on for syringomyelia, and we completed entering their information at the time of the operation.

PROTOCOL FOR EXAMINING DYSHIDROSIS

We obtained detailed clinical information for each patient, including their previous experience of hidrosis. A structured protocol was used to examine the state of hidrosis: step 1 asking about the nature and distribution of the hidrosis and the effects of room temperature, exercise, clothing, psychological burdens, food, etc; step 2 examining the state of hidrosis by observation, manual examination, and drawing a metal spoon across the surface of the skin (spoon test ${ }^{12}$ ) either after adequate physical exercise or when lying in a bed warmed in advance by electric blankets. When further investigation was necessary to clarify the nature and distribution of dyshidrosis, the following steps were performed; step 3 taking a thermograph in a room at a temperature of $21-28^{\circ} \mathrm{C}$; step 4 a hidrosis examination (the iodine-starch method) at a room temperature of $45-50^{\circ} \mathrm{C}$, or in a bed warmed in advance. Consequently we 

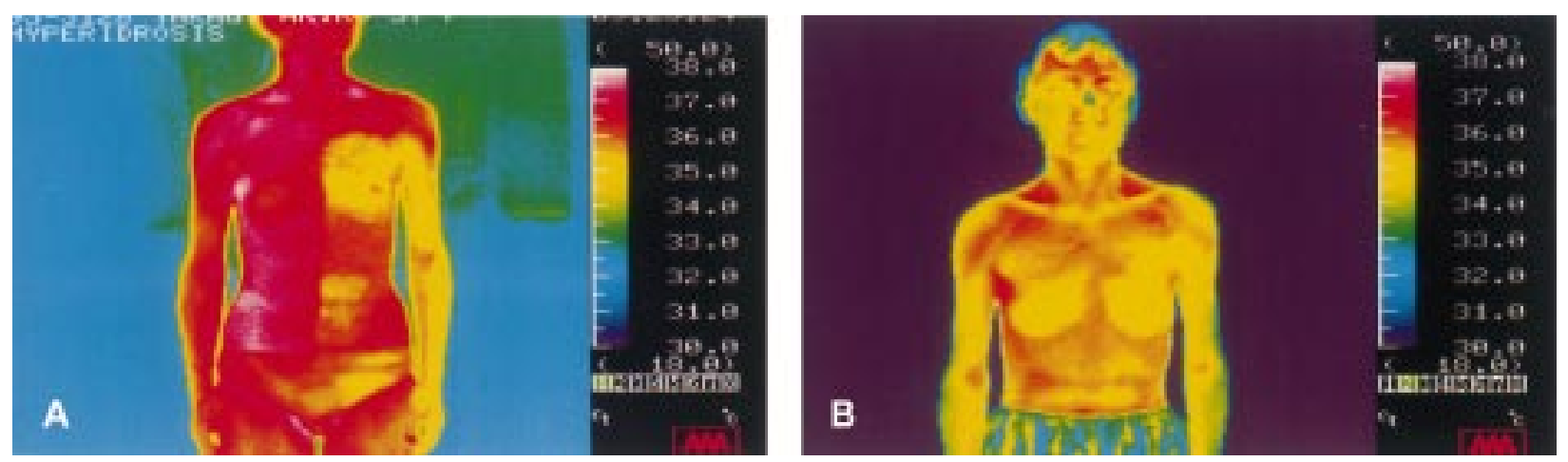

Thermograph of patient 18 before $(A)$ and 11 days after (B) surgical decompression of syrinx (anterior views). Temperature asymmetry has resolved immediately after decompression of the syrinx.

performed thermography in 16 patients, and the iodine-starch method in nine patients. We assessed the performance status by Karnofsky performance score ( $\mathrm{K}$ score); this ranges from 0 to 100 , and the higher the score, the better the performance. ${ }^{13}$

CASE RECORDS

(See also our previous case records for three patients with hyperhidrosis $\left.{ }^{14}\right)$.

Patient 18 (hyperhidrosis; 37 year old woman) had a 7 month history of persistent hyperhidrosis and pain in the left upper quadrant of the body. There was no muscle weakness or atrophy. Thermography showed low temperature in the left upper quadrant, which was consistent with hyperhidrosis of the area (figure A). She underwent an operation (a syringosubarachnoid shunt) 7 months after onset, after which hyperhidrosis and pain subsided within a week, as indicated by thermography (figure B).

STATISTICAL ANALYSIS

We performed a statistical analysis of five factors (age at time of study, age of onset of symptoms, duration from onset of symptoms to time of study, $\mathrm{K}$ score, and duration of follow up period) for the three groups of patients (hyperhidrosis, normohidrosis, and hypohidrosis) by one way factorial analysis of variance (ANOVA) (Fisher's PLSD method as a post hoc test), and for two factors (age of onset of current dyshidrosis and duration from onset of symptoms to current dyshidrosis) between the two groups of patients (hyperhidrosis and hypohidrosis) by non-paired $t$ test. We then obtained the Pearson's correlation coefficient for duration from onset of symptoms to time of study, and $\mathrm{K}$ score for all 30 patients.

\section{Results}

Of the 30 patients, eight $(26.7 \%)$ had hypohidrosis, $10(33.3 \%)$ had segmental hyperhidrosis, and $12(40 \%)$ had normohidrosis. In all patients, the distribution of dyshidrosis corresponded with the location of the syrinx and other neurological manifestations; the syrinx was located roughly in the region from the central canal to the unilateral (or sometimes bilateral with asymmetry) posterior angle of the spinal cord.

We have summarised the results of the statistical analyses in the table. Although we

Table 1 Summary of evaluation of each item

\begin{tabular}{|c|c|c|c|c|}
\hline Item & Hypohidrosis & Hyperhidrosis & Normohidrosis & $p$ Value \\
\hline Number of patients & 8 & 10 & 12 & \\
\hline \multicolumn{5}{|l|}{ Age at time of study: } \\
\hline Range (y) & $17-71$ & $18-75$ & $19-75$ & \\
\hline Mean (SD) & $45.4(22.7)$ & $39.2(17.9)$ & $42.9(18.8)$ & $0.7982^{\star}$ \\
\hline \multicolumn{5}{|c|}{ Age of onset of symptoms: } \\
\hline Range (y) & $2-55$ & $5-45$ & $10-69$ & \\
\hline Mean (SD) & $21.5(16.4)$ & $23.8(13.6)$ & $33.3(16.2)$ & $0.2008^{\star}$ \\
\hline \multicolumn{5}{|c|}{ Duration from onset of symptoms to study: } \\
\hline Range (y) & $8-45$ & $1-33$ & $1-32$ & \\
\hline Mean (SD) & $23.9(13.3)$ & $15.5(10.1)$ & $9.67(9.61)$ & $0.0273^{\star} \|$ \\
\hline \multicolumn{5}{|c|}{ Karnofsky performance score: } \\
\hline Range & $50-90$ & $60-90$ & $70-90$ & \\
\hline Mean (SD) & $65.0(16.9)$ & $85.0(9.72)$ & $83.3(6.51)$ & $0.0012 \star \$ 9$ \\
\hline \multicolumn{5}{|l|}{ Follow up period: } \\
\hline Range (y) & $1-9$ & $1-9$ & $1-8$ & \\
\hline Mean (SD) & $3.38(3.25)$ & $5.00(3.74)$ & $2.83(2.76)$ & $0.2960^{\star}$ \\
\hline \multicolumn{5}{|c|}{ Age of onset of current dyshidrosis: } \\
\hline Range (y) & $16-66$ & 13.50 & - & \\
\hline Mean (SD) & $42.3(21.0)$ & $29.2(13.5)$ & - & $0.1287 \dagger$ \\
\hline \multicolumn{5}{|c|}{$\begin{array}{l}\text { Duration of onset from symptoms to current } \\
\text { dyshidrosis: }\end{array}$} \\
\hline Range (y) & $7-45$ & $0-15$ & - & \\
\hline Mean (SD) & $12.6(4.5)$ & $5.50(4.70)$ & - & $0.0027+\$$ \\
\hline
\end{tabular}

* One way factorial ANOVA (Fisher's PLSD method).

†Non-paired $t$ test.

$§$ Statistically significant.

$\|$ p value for each pair of items: hyperhidrosis $v$ hypohidrosis 0.1148 ; hypohidrosis $v$ normohidrosis 0.0078 ; normohidrosis $v$ hyperhidrosis 0.2194 .

Ip value for each pair of items: hyperhidrosis $v$ hyperhidrosis 0.0007 ; hypohidrosis $v$ normohidrosis; 0.7282 ; normohidrosis $v$ hypohidrosis 0.0012 . 
ourselves were not able to confirm any change in the features of hidrosis during the follow up period, the clinical histories of five patients indicate that hidrosis decreased segmentally or diffusely over a long period. Duration from onset of symptoms to study was significantly longer in the hypohidrosis group than the normohidrosis group (ANOVA; $F(2,27)=4.127$, $\mathrm{p}=0.0273$ ) (table). The K scores were significantly higher in the hyperhidrosis and normohidrosis groups than in the hypohidrosis group (ANOVA; $F(2,27)=8.765, \mathrm{p}=0.0012$ ), with no significant difference between the hyperhidrosis and normohidrosis groups $(\mathrm{p}=0.7282)$. Duration from onset of symptoms to current dyshidrosis was significantly longer in the hypohidrosis than in the hyperhidrosis group $(p=0.0027)$. There were no significant differences between hidrosis groups in the other factors. A significant correlation between the two items (duration from onset of symptoms to study, and K score) was recognised ( $r=-0.599$, $\mathrm{n}=30, \mathrm{p}=0.0003$ ).

\section{Discussion}

We performed a MEDLINE search for publications dealing with dyshidrosis in syringomyelia between January 1966 and June 1997, with a language limitation of English, German, and French. This search confirmed the scant accumulation of information regarding dyshidrosis in syringomyelia; we were able to locate only four cases accompanied by Chiari malformation (three of which we have already reported and are currently included in this study). ${ }^{14}$

We previously speculated that hyperhidrosis is caused by stimulation of sympathetic preganglionic neurons (SPGNs) rather than interference to the inhibitory tract. ${ }^{14}$ This is equivalent to the hypothesis regarding body hypertrophy which we recently presented. ${ }^{4}$ Later, disinhibition of the inhibitory local interneurons (ILINs), which are located in the vicinity of SPGNs, was supposed to be the cause of segmental hyperactivity of the SPGNs. ${ }^{10}$ When, in the clinical course of syringomyelia, slowly progressive tissue damage around the syrinx ${ }^{3}$ reaches the lateral horn, it will segmentally affect the SPGNs or adjacent structures. ${ }^{14}$ This time our results have shown, from the viewpoint of sweating, that there evidently is a hyperactivity of the SPGNs as long as the disability is mild; however, as the disability progresses, the hyperactivity gradually decreases and is replaced by hypoactivity (table).

We have a choice of two possibilities for the mechanism responsible for the hyperactivity of the SPGNs so far; the first is that the SPGNs are stimulated directly by a minimal tissue damage; the second is damage to the ILINs ${ }^{10}$ (preceding the damage to the SPGNs)-we have recently acquired some knowledge of these ILINs. ${ }^{15}{ }^{16}$ In either case, as the disease progresses, hyperactivity will shift to normoactivity and finally to hypoactivity because of progressive and irreversible damage to the
SPGNs, consistent with the clinical history of five of our eight patients with hypohidrosis. By contrast, immediate resolution of hyperhidrosis after decompression of the syrinx in patient 18 , whose disability was minimal, showed that the damage to the SPGNs was mild and tends to be reversible in patients with mild disability (figure). Before we reached the above hypothesis for the mechanism of hyperhidrosis, we had ruled out the possibility of interference to the inhibitory tract that connects the upper centre and the SPGNs as before because of the segmental distribution of hyperhidrosis and because of the locational relation among the syrinx, inhibitory tracts, and SPGNs. ${ }^{14} 16$

Current results substantiate previous speculation about the mechanism of and relation between hyperhidrosis and hypohidrosis in syringomyelia. ${ }^{3914}$ We now think that, in syringomyelia, focal hyperhidrosis can be regarded as a hallmark of a relatively intact-even though slightly damaged-spinal cord. We also think that, in syringomyelia, some part of normohidrosis is associated with a considerable amount of spinal cord damage. We propose that in diagnosing focal dyshidrosis, more attention should be given to the possibility of syringomyelia.

We are indebted to Drs Kazutoshi Hida, Yoshinobu Iwasaki, and Hiroshi Abe (Department of Neurosurgery, Hokkaido University School of Medicine) for their help in providing us with clinical information regarding surgical treatment. This study was supported by Research Grant (5B-3) for Nervous and Mental Disorders, from the Japanese Ministry of $H$ ealth and Welfare.

1 Spillane JD. Syringomyelia. An atlas of clinical neurology. London: Oxford University Press, 1968:254-63.

2 Foster JB, Hudgson P. The clinical features of communicatng syringomyelia. In: Barnett HJM, Foster JB, Hudgson P, eds. Syringomyelia. London: WB Saunders, 1973:16-29.

3 Schliep G. Syringomyelia and syringobulbia. In: Vinken PJ, Bruyn GW, eds. Handbook of clinical neurology. Amsterdam: North-Holland, 1978:255-327.

4 Sudo K, Owada Y, Yabe I, et al. Syringomyelia as a cause of body hypertrophy. Lancet 1996;347:1593-5.

5 Nudleman K, Andermann E, Andermann F, et al. The hemi 3 syndrome. Hemihypertrophy, hemihypaesthesia, hemi3 syndrome. Hemihypertrophy, hemihypaesth

6 Mancall EL. Syringomyelia. In: Rowland LP, ed. Merritt's textbook of neurology. 8th ed. Philadelphia: Lea and Febiger, 989:687-91.

7 Adams RD, Victor M, Ropper AH. Syringomyelia. In: Adams RD, Victor M, Ropper AH, eds. Principles of neurology. 6th ed. New York: McGraw-Hill, 1997;1269-77.

8 Finlayson AI. Syringomyelia and related conditions. In: Joynt RJ, eds. Clinical neurology. Philadelphia: LippincottRaven, 1995;1-17.

9 Döring G. Zur Klinik vegetativer Störungen bei Syringomyelie und über trophische Störungen im allgemeinen. Dtsch Med Wochenschr 1949;74:754-9.

10 Stovner LJ, Sjaastad O. Segmental hyperhidrosis in two sibings with Chiari type I malformation. Eur Neurol 1995;35: 149-55.

11 Johnson RH, Lambie DG, Spalding JMK. Syringomyelia and related conditions. In: Joynt RJ, ed. Clinical neurology. and related conditions. In: Joynt RJ, ed. Cline

12 Pryse-Phillips W. Companion to clinical neurology. In: Pryse-Phillips W, eds. Boston: Little, Brown, 1995;812.

13 Milstein JM, Cohen ME, Sinks LF. The influence and reliability of neurologic assessment and Karnofsky performance score on prognosis. Cancer 1985;56:1834-6.

14 Sudou K, Tashiro K. Segmental hyperhidrosis in syringomyelia with Chiari malformation. F Neurol 1993;240:75-8.

15 Berry MM, Standring SM, Bannister LH. Autonomic nervous system. In: Williams PL, ed. Gray's anatomy. 38th ed. New York: Churchill Livingstone, 1995:1292-312.

16 Lewis DI, Coote JH. Chemical mediators of spinal inhibition of rat sympathetic neurones on stimulation in the nucleus tractus solitarii. F Physiol (London) 1995;486:483- 


\section{LETTERS TO THE EDITOR}

Behavioural status during the (Wada test): relevance for surgical management $(\mathcal{F}$ Neurol Neurosurg Psychiatry 1999;67:549-559)

Presurgical evaluation in many epilepsy programmes often includes the intracarotic amobarbital procedure (IAP). Sodium amytal is injected into the internal carotid artery to produce a temporary "pharmacological paralysis" of hemispheric function. Traditionally, the IAP has been employed in patients with refractory temporal lobe epilepsy being considered for anterior temporal lobectomy. In these cases it is used to determine cerebral dominance for language, to assess the risk of severe postsurgical amnesia ${ }^{2}$ and to predict postsurgical material specific memory changes. ${ }^{3}$ More recently, the use of the IAP has been extended to compliment EEG localisation and radiological data by lateralising temporal lobe dysfunction. ${ }^{4}$

The IAP may have a hitherto unrecognised role in patients with refractory frontal lobe epilepsy being considered for frontal lobectomy. Specifically, observation of behavioural function during the period of the ablation may provide useful information about the integrity of the contralateral frontal lobe. This is particularly relevant in those candidates with a history of cerebral trauma in whom damage to the bifrontal lobe is known or suspected. A review of the IAP studies performed on patients with temporal lobe epilepsy in our comprehensive epilepsy programme (1991-8) suggests that the emergence of frontal lobe behavioural features is common in patients in whom the aetiology leads to the suspicion of bifrontal compromise (for example, a history of traumatic head injury). By contrast, these features rarely emerge in cases of non-traumatic aetiology, in which the integrity of frontal lobe systems is presumed. Although it remains an incidental finding in the context of determining the suitability of a candidate for anterior temporal lobectomy, this outcome may have potential implications for the selection of patients for frontal lobectomy.

We report a case of frontal lobe epilepsy secondary to a traumatic head injury. Out of concern for untoward postoperative behavioural change, we employed the IAP in an attempt to predict the risk of a frontal lobe syndrome.

A 39 year old man had a 23 year history of severe refractory epilepsy. The seizures postdated a motor car accident at the age of 12 years when he sustained a head injury with an ill defined period of loss of consciousness. Seizures commenced within months of that injury and, although initially well controlled, became refractory within a few years. The seizure types included staring spells, violent tonic-clonic seizures, and atonic drop attacks. He had complications from his epilepsy including a fractured jaw, two episodes of severe burning due to seizures while showering, multiple episodes of postictal confusion and probable postictal psychosis, a lung abscess secondary to aspiration, and episodes of status epilepticus. Interictal EEG recordings showed bilateral generalised spike and wave discharges at around 2
$\mathrm{Hz}-2.5 \mathrm{~Hz}$ with some mild increase in bilateral slow activity and no convincing evidence of electrographic focalisation. Video EEG monitoring showed apparent generalised seizures without any focal onset on scalp EEG. Brain MRI disclosed a well defined atrophic lesion involving the left frontal pole considered likely to be post-traumatic in origin. Interictal FDG PET and HMPO SPECT disclosed hypoperfusion in the left anterior frontal region commensurate with the abnormality shown on MRI. Although his electroclinical pattern was suggestive of symptomatic generalised epilepsy, because of the left frontal lesion, seizure onset from that region was considered likely.

On neuropsychological examination, his general cognitive function was normal. At a behavioural level, however, he presented as very peurile in manner with a very rigid, inflexible cognitive style. The neuropsychological opinion was of a mild frontal lobe syndrome consistent with the history of traumatic head injury. There was no current evidence of psychiatric disorder. Although having successfully passed his final year of secondary school (together with several courses of advanced education), he had remained unemployed due to his seizures. $\mathrm{He}$ was socially isolated and his interpersonal relationships were limited.

He had severe life threatening epilepsy with the surgical option the only remaining avenue of treatment. However, as surgical management would involve resection of the left frontal lobe against a background of traumatic head injury and the possibility of more generalised frontal lobe compromise, a left hemispheric IAP was performed. Sodium amytal $(125 \mathrm{mg}$ ) was administered via a slow hand injection. Of relevance, no crossflow into the contralateral anterior cerebral artery via the anterior communicating artery was present (as assessed by a separate injection of contrast medium). The injection was accompanied by a dense right hemiplegia and global aphasic arrest. Resolution of language was characterised by a dense perseveration of counting which could not be influenced by the examiner. Despite normal comprehension, he showed severely impaired capacity for motor regulation (go-no go paradigm), together with marked behavioural disinhibition (agitation, swearing, verbosity, childishness). Although seemingly aware of some aspects of his behaviour (apologising for swearing), he seemed unable to modify his responses. The overall impression was of a pronounced frontal lobe syndrome, suggesting that the right frontal lobe had incurred some damage secondary to the documented head trauma and that he must have been reliant on some left frontal contribution.

On the basis of the IAP findings, a selective cortical resection (as opposed to more extensive frontal lobectomy) restricted to the region of damage was advised. Intraoperative electrocorticography showed active focal epileptiform discharges maximal in the inferior frontal lobe in the electrodes closest to the lesion. A cortical resection was performed with frameless stereotaxy guidance excision of the frontal lesion. Histopathology on the resected tissue showed an old post-traumatic cyst involving the cortex and white matter. His postoperative course was unremarkable. When reviewed 3 months after surgery he was seizure free. His performance on neuropsychological evaluation remained commensurate with presurgical status. There were no novel subjective complaints. Mood, behaviour, and temperament remained stable.
Despite its undoubted value in many individual cases of temporal lobe epilepsy, the IAP has remained a controversial assessment instrument. ${ }^{5}$ Amid this controversy its potential usefulness in other patient groups seems to have been overlooked. A primary criticism of its use in temporal lobe epilepsy has been the question of irrigation and whether the medial temporal lobe is adequately "disabled" during the procedure. This particular limitation is not applicable when used in the patient with frontal lobe epilepsy, as the region of interest is clearly ablated via supply from the carotid arterial system. Caution must, however, be exercised with respect to possible crossflow into the contralateral anterior cerebral artery via the anterior communicating artery. When such crossflow is present, the ability to assess validly the integrity of contralateral frontal lobe function will be confounded by virtue of a pharmacologically induced bilateral frontal lobe syndrome. As with the use in cases of temporal lobe epilepsy, only a restricted form of assessment is possible with the frontal lobe patient during the period of ablation. An assessment focusing on issues of behavioural regulation would seem most useful.

It should be borne in mind that the degree of frontal lobe dysfunction induced by the IAP represents the "worst case scenario" as the entire frontal lobe is included in the ablation. There are likely to be few surgical scenarios in which a comparable extensive resection of tissue is likely to be considered, and results must be interpreted in this context. This limitation not withstanding, the IAP does seem to have a role in separating out those patients in whom more extensive frontal lobe resections could be considered as opposed to those in whom a more conservative approach is warranted.

This case report forms only the basis for a novel hypothesis that clearly requires more rigorous scientific research before its clinical utility can be reliably established. Nonetheless, we think that it is worth drawing the attention of the epileptological community to the potential application of the IAP in the surgical management of extratemporal cases.

MARIE F O'SHEA MICHAEL M SALING

Department of Neuropsychology SAMUEL F BERKOVIC

Department of Neurology, Austin and Repatriation Medical Centre, Melbourne, Australia; and Department of Medicine, University of Melbourne, Grattan Street, Parkville 3052, Australia.

Correspondence to: Dr Marie F O'Shea, Department of Neuropsychology, Austin and Repatriation Medical Centre (Austin Campus), Studley Road, Heidelberg, Victoria 3084, Australia. Telephone 6133039496 5913; Fax 61330394572654.

Wada J, Rasmussen T. Intracarotid injection of sodium amytal for the lateralization of cerebral speech dominance: experimental and clinical observations. I Neurosurg 1960;17:266-82.

2 Rausch R, Silfveius H, Weiser H-G, et al. Intraarterial amobarbital procedures. In: Engel J, ed, Surgical treatment of the epilepsies. 2nd ed. New York: Raven Press, 1993:341-57.

3 Kneebone AC, Chelune GJ, Dinner DS, et al. Intracarotid amobarbital procedure as a predictor of material-specific memory change after anterior temporal lobectomy. Epilepsia 1995; 36:857-65

4 Baxendale SA, Van Paesschen W, Thompson PJ, et al. The relation between quantitative MRI measures of hippocampal structure and the intracarotid amobarbital procedure. Epilepsia 1997;38:998-1007.

5 Jones-Gotman M, Barr WB, Dodrill CB, et al. Controversies concerning the use of intraarterial procedures. In: Engel J, ed. Surgical treatment of the epilepsies. 2nd ed. New York: treatment of the epilepsies. 
Reversal of tetrabenazine induced depression by selective noradrenaline (norepinephrine) reuptake inhibition

Tetrabenazine (TBZ), a synthetic benzoquinolizine, was first introduced as a neuroleptic agent in 1960, and is now widely used in the treatment of hyperkinetic movement disorders such as chorea, tics, or tardive dyskinesia. The side effect profile is mainly characterised by the triad of drowsiness/ fatigue, parkinsonism, and depression; depression is found in about $15 \%$ of patients treated with TBZ. ${ }^{1}$ We here report on the rapid reversal of depressive symptoms in a patient treated with TBZ for orofacial dystonia by administering the new and highly selective noradrenaline (norepinephrine) reuptake inhibitor (SNRI) reboxetine. ${ }^{2}$

On admission, the 64 year old woman presented with perioral and lingual hyperkinesias as well as intermittent and involuntary movements of her lower jaw, which had lasted for about 2 years, causing her a considerable impairment of articulation. No history of neuroleptic treatment or Parkinson's disease was evident. Her cranial CT and blood chemistry were normal. We diagnosed a segmental dystonia, which improved dramatically after initiation of a tetrabenazine medication (60 $\mathrm{mg}$ a day). This successful treatment response, however, was accompanied by a severe depressive syndrome, which was characterised by a mixed anxiousdepressive mood, low self esteem, a complete loss of drive, and intermittent suicidal ideations. After switching from TBZ to tiapride, the patient recovered from depression, but her neurological status worsened significantly. The re-exposure to TBZ again ameliorated hyperkinesia, but provoked a depressive relapse. A comedication with reboxetine $(6 \mathrm{mg} /$ day $)$, a new and selective noradrenaline reuptake inhibitor, finally led to a stable remission of the depressive symptoms within a week, without any worsening of the dystonic syndrome.

Tetrabenanzine (TBZ) is known to act as a monoamine depleting and dopamine receptor blocking drug. ${ }^{1}$ In more detail, TBZ binds to and inhibits specifically the human vesicular monoamine transporter isoform 2 (hVMAT2). Whereas the indolamine serotonin (5-HT) performs a similar affinity for both hVMAT1 and hVMAT2, catecholamines such as noradrenaline exhibit a threefold higher affinity for hVMAT2.. As these specific transporters are responsible for packaging monoamine neurotransmitters into presynaptic secretory vesicles for release by exocytosis, the inhibition of hVMAT2 by compounds such as tetrabenazine thus results in consecutive noradrenaline depletion. ${ }^{4}$

Alterations of noradrenergic neurotransmission - that is, a neuronal noradrenaline depletion-can therefore be postulated to form one major origin of TBZ induced depression. In line with this assumption, brain-specific catecholaminergic activity enhancers (CAEs) such as phenylethylamine have been shown to antagonise TBZ induced depression-like behaviour in rats. ${ }^{5}$ Modulating this altered noradrenergic neurotransmission pattern by the administration of selective noradrenaline reuptake inhibitors such as reboxetine may thus provide a new, specific, and fast acting tool in the management of depression caused by TBZ and related (neuroleptic) compounds.
WOLFGANG SCHREIBER JÜRGEN-CHRISTIAN KRIEG Department of Psychiatry and Psychotherapy, Philipps-University, Rudolf-Bultmann-Straße 8, D-35033 Marburg/Lahn, Germany TOBIAS EICHHORN Department of Neurology, Philipps-University Rudolf-Bultmann-Straße 8, D-35033 Marburg/Lahn, Germany

Correspondence to: Dr Wolfgang Schreiber, Department of Psychiatry and Psychotherapy, Philipps-University, Rudolf-Bultmann-Straße 8, D-35033 Marburg/Lahn, Germany. Telephone 00496421 286277; fax 00496421 285229; email schreibe@mailer.uni-marburg.de

1 Jankovic J, Beach J. Long-term effects of tetrabenazine in hyperkinetic movement disorders. Neurology 1997;48:358-62.

2 Montgomery S. Reboxetine: additional benefits to the depressed patient. $\mathcal{F}$ Psychopharmacol to the depressed patient.

3 Erickson JD, Schäfer MK, Bonner TI, et al. Distinct pharmacological properties and distributinct pharmacological properties and distribution in neurons and endocrine cells of two isoforms of the human vesicular monoamine transporter. Proc Natl Acad Sci U S A 1996;93: 5166-71.

4 Hoffman BJ, Hansson SR, Mezey E, et al. Localization and dynamic regulation of biogenic amine transporters in the mammalian central nervous system. Front Neuroendocrinol 1998;19:187-231.

5 Knoll J, Miklya I, Knoll B, et al. Phenylethylamine and tyramine are mixed-acting sympathomimetic amines in the brain. Life Sci 1996;58:2101-14.

Spinal sulcal artery syndrome due to spontaneous bilateral vertebral artery dissection

In young adults vertebral artery dissection (VAD) is an important cause of brain infarction. ${ }^{12} \mathrm{~A}$ known mechanism is microtraumata due to abrupt head movementsfor example, chiropractic manoeuvres. In addition a pathogenetic role of connective tissue diseases, cystic media necrosis, fibromuscular dysplasia, migraine, and inflammatory diseases has been postulated. ${ }^{3}$ In VAD initial neck pain is often reported, which may be slight. Lesions caused by VAD are cerebellar or brainstem infarcts, unilateral or bilateral thalamic infarcts (top of the basilar syndrome), or infarctions in the posterior cerebral artery territory due to intra-arterial embolism or haemodynamic decompensation when collaterals are insufficient. ${ }^{1}$ Lesions of the cervical spinal cord are rare because of its good collateral supply. ${ }^{45}$ We report on a patient with a syndrome of the spinal sulcal artery (incomplete Brown-Séquard syndrome) caused by spontaneous bilateral VAD.

A 43 year old man with a history of arterial hypertension presented with left sided numbness sparing the face, which had evolved suddenly while he was walking. In addition, he reported on dull right sided neck pain irradiating into the occiput, which had been initiated by a head rotation while he was working at a computer 2 weeks before. The neck pain had spontaneously ceased 6 days later. Neurological examination disclosed dissociated sensation defect on the left with an indistinct level around C4 to C6. Below this level on the left he had a marked hypalgesia and nearly a loss of temperature sense. The right limbs were warmer than the left ones. In addition, we found mild right sided motor system deficits. Cranial nerve function was intact, despite a right sided Horner's syndrome. According to chest radiography phrenic nerve function was preserved. Routine laboratory findings including CSF analysis were normal. The hemiparesis and the different temperature sensation in the limbs resolved completely within 3 weeks.

Tibial nerve somatosensory evoked potentials (SSEPs) had regular N22 and P40 latencies and amplitudes. Central motor conduction time (CMCT) after transcranial magnetic stimulation was prolonged to the right abductor digiti minimi $(9.2 \mathrm{~ms})$ and tibialis anterior $(23.1 \mathrm{~ms})$. The CMCT to the left target muscles was normal. Duplex sonography showed increased flow velocity on the level of the cervical vertebrae 3 to 5 with a maximum of $214 \mathrm{~cm} / \mathrm{s}$ in the right and $197 \mathrm{~cm} / \mathrm{s}$ in the left vertebral artery. Colour mode showed irregular narrowings of the lumen indicating dissections.

Cervical MRI showed a spinal cord infarction at the level C2 (figure). The circumference and dorsal part of the cord were not affected. In digital subtraction angiography (DSA) both vertebral arteries had string signs in the V1 and V2 segments with collateral flow to the distal V2-4 segments via the thyreocervical trunk (cervical ascendent artery) and the costocervical trunk also. The anterior spinal artery was incompletely contrasted by unilateral spinal branches of the right vertebral artery. They originated at the level of dissection. The intradural origins of the anterior spinal artery from the distal part of the vertebral arteries (V4 segment) were not visible.

Bilateral spontaneous VAD is not rare, but often missed. In most cases, microtrauma preceding the dissection can be recalled by the patients. Due to the mild mechanical impact, the action of predisposing factors might be postulated. Among these may be changing in type III collagen, migraine, fibromuscular dysplasia, infections in the near past, and inflammatory vasculopathy. ${ }^{2}$ Magnetic resonance imaging with typical semilunar mural haematoma and in addition magnetic resonance angiography (MRA) with complementary documentation of an irregular lumen or tapering occlusion have a high sensitivity and specificity in cases of internal carotid artery dissection. ${ }^{1}$ By contrast, mural haematomas of the VA especially in the V1 and the V3 segments are often not detectable by MRI. In cases of unclear non-invasive findings, DSA is still the method of choice.

In addition to consecutive brain infarctions, cervical spinal cord infarctions and nerve root compression syndromes may occur in cases of unilateral or bilateral VAD. Probably as a result of the pial collateral network and the dual posterior spinal artery, spi-

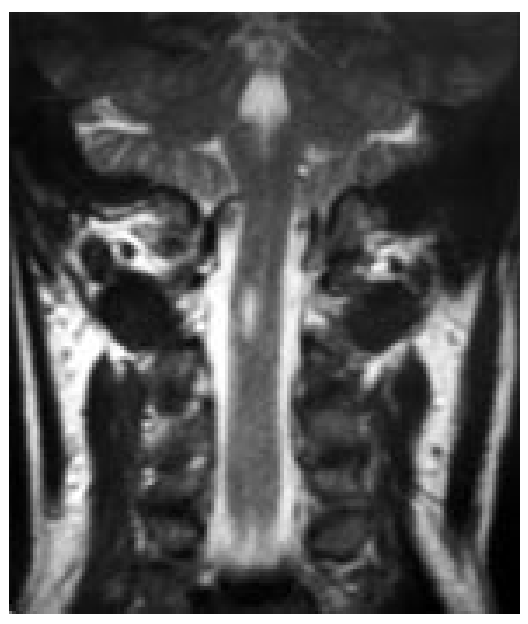

Coronal T2 weighted MRI: ventrolateral paramedian right sided medullary infarction. 
nal cord infarction is often located in the anterior spinal artery territory with the grey matter of the anterior horns exhibiting the highest vulnerability to ischaemia. ${ }^{45}$ This mechanism may lead to a typical "snake eye" configuration of medullary infarction. ${ }^{3} \mathrm{Be}-$ sides the supply via VA spinal branches, which is found in $19 \%$ only unilaterally, there are branches originating from the ascendant cervical artery (thyreocervical trunk) and the costocervical trunk supplying the spinal cord.

DSA findings in the present case suggest that spinal branches originating from the right V2 segment were dominant feeders of the anterior spinal artery whereas there was no evidence of direct communication between vertebral and spinal arteries from the V4 segment. The dissection involved the V2 segment from which these spinal branches originate. A transient occlusion of these spinal branches is a likely consequence. This unusual type of arterial medullary supply may explain why VAD causes spinal cord infarction. Contrary to Pullicino, ${ }^{5}$ who described upper limb atrophies due to cervical spinal cord infarction involving the anterior horns, the present case shows a unilateral involvement of commissural, spinothalamic, pyramidal, and vasoconstrictor tracts. To our knowledge sulcal spinal artery syndrome caused by bilateral spontaneous VAD has not yet been described. In conclusion, differential diagnosis of acute spinal symptoms in young adults should include spontaneous unilateral or bilateral VAD with cervical spinal cord ischaemia.

\section{$S$ WEIDAUER}

D CLAUS

Department of Neurology

M GARTENSCHLÄGER

Institute for Radiology, Klinikum Darmstadt, Teaching Hospital University Frankfurt, Germany Correspondence to: Professor D Claus, Department of Neurology, Klinikum Darmstadt, Teaching Hospital University Frankfurt, Heidelberger Landstrasse 379, 64297 Darmstadt, Germany.

1 Auer AS, Felber S, Schmidauer C, et al. Magnetic resonance angiographic and clinical features of extracranial vertebral artery dissection. I Neurol Neurosurg Psychiatry 1998;64:474-81.

2 Caplan LR, Zarins CK, Hemmati M. Spontaneous dissection of the extracranial vertebral arteries. Stroke 1985;16:1030-8.

3 Hundsberger T, Thömke F, Hopf HC, et al. Symmetrical infarction of the spinal cord due to spontaneous bilateral vertebral artery dissection. Stroke 1998;29:1742.

4 Kaneki M, Inoue K, Shimizu T, et al. Infarction of the unilateral horn and the lateral column of of the sinal cord with sparing of posterior
the spinal the spinal cord with sparing of posterior
columns: demonstration by MRI. $\mathcal{F}$ Neurol columns: demonstration by MRI. $\mathcal{F}$
Neurosurg Psychiatry 1994;57:629-31.

5 Pullicino P. Bilateral distal upper limb amyotrophy and watershed infarcts from vertebral dissection. Stroke 1994;25:1870-2.

Spanish families with cavernous angiomas do not share the HispanoAmerican CCM1 haplotype

Cerebral cavernous malformations are vascular malformations mostly located in the CNS. Their frequency is estimated close to $0.5 \%$ in the general population. ${ }^{1}$ Cerebral cavernous malformations occur as a sporadic or hereditary condition. From the Hispano-American population, familial forms were reported with a high frequency. ${ }^{2} C C M 1$, a hitherto unidentified gene mapping on chromosome 7 was shown to be involved in all families with cerebral cavernous malformations of Hispano-
American descent with a strong founder effect. $^{23}$ Around $50 \%$ of non-HispanoAmerican families showed linkage to CCM1 but no common haplotype was found. ${ }^{45} \mathrm{~A}$ recent study showed linkage of cerebral cavernous malformations to two additional loci. ${ }^{5}$ No Spanish family with cerebral cavernous malformations has been analysed so far.

We report herein a genetic linkage analysis conducted on nine Spanish families with cerebral cavernous malformations. All procedures were approved by an ethics comittee. The families were unrelated and originated from different regions of Spain (south west (CVE2, 3, 4, 10, 17, 25), central (CVE24),
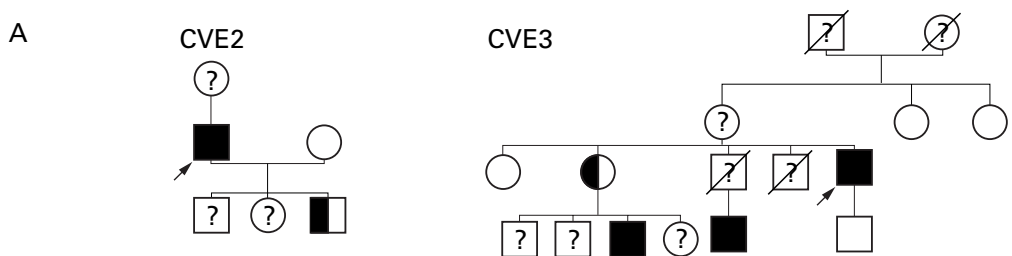

$$
\text { CVE4 }
$$
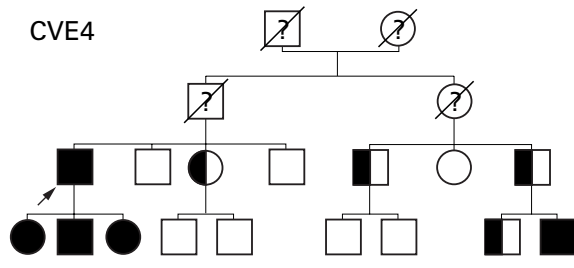

CVE17

CVE24

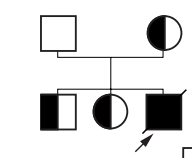

CVE28
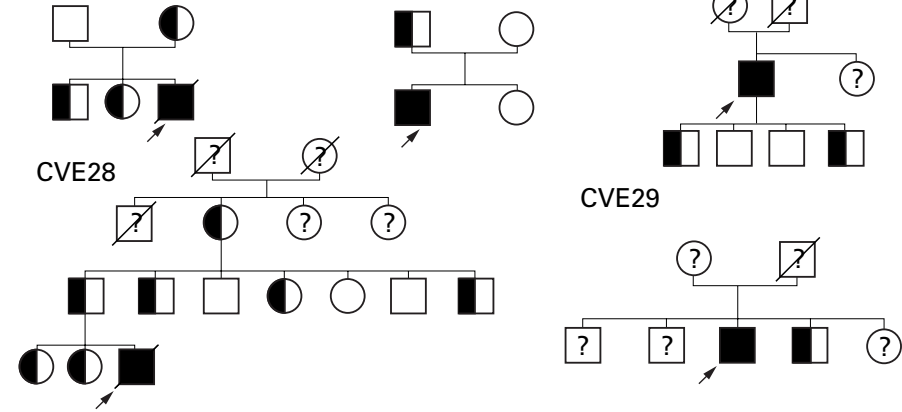

B

\begin{tabular}{|c|c|c|c|c|c|c|c|c|c|c|c|c|}
\hline \multirow{2}{*}{$\frac{\text { Marker }}{\text { D7S2410 }}$} & $\begin{array}{l}\text { Hispanic- } \\
\text { American }\end{array}$ & \multirow{2}{*}{$\begin{array}{l}\text { CVE2 } \\
273\end{array}$} & \multirow{2}{*}{$\begin{array}{c}\text { CVE3 } \\
265\end{array}$} & \multirow{2}{*}{$\begin{array}{c}\text { CVE4 } \\
269\end{array}$} & \multirow{2}{*}{$\begin{array}{r}\text { CVE10 } \\
265\end{array}$} & \multirow{2}{*}{$\begin{array}{c}\text { CVE24 } \\
265\end{array}$} & \multirow{2}{*}{$\begin{array}{c}\text { CVE25 } \\
267\end{array}$} & \multirow{2}{*}{$\begin{array}{c}\text { CVE28 } \\
263\end{array}$} & \multicolumn{2}{|c|}{ CVE17 } & \multicolumn{2}{|c|}{ CVE29 } \\
\hline & $0 \quad 279$ & & & & & & & & 265 & 263 & 263 & 269 \\
\hline S2409 & $9 \mathrm{ND}$ & 221 & 219 & 215 & 1 & 19 & 219 & 223 & 219 & 223 & 223 & 219 \\
\hline 1813 & $\begin{array}{ll}3 & 137\end{array}$ & 12 & & & & & 1 & 131 & 125 & 127 & 127 & 127 \\
\hline D7S1789 & $9 \quad 137$ & 139 & 133 & 33 & 129 & 131 & 133 & 129 & 129 & 133 & 129 & 133 \\
\hline 0000 & $\mathrm{NL}$ & 13 & & & & 135 & 133 & 129 & ND & ND & 137 & 133 \\
\hline D7S646 & 185 & 185 & 185 & 87 & 197 & $183 \mid 185$ & 5181 & 187 & 197 & 201 & 197 & 185 \\
\hline D7S558 & 107 & 107 & 107 & 103 & 107 & 103 & 103 & 103 & 103 & 103 & 103 & 103 \\
\hline D7S689 & 129 & 127 & 125 & 129 & 127 & 127 & 139 & 127 & 125 & 127 & 129 & 127 \\
\hline
\end{tabular}

(A) Pedigrees of the nine families with cerebral cavernous malformations. Black symbols=symptomatic patients with cavernous angiomas on MRI; half filled symbols=asymptomatic members with cavernous angiomas on MRI; empty symbols=asymptomatic members with normal MRI; question mark=members with unknown status. (B) Comparison of the Hispano-American CCM1 haplotype and the haplotypes segregating with the disease phenotype within Spanish families. Polymorphic markers are shown on the left. Numbers indicate the sizes in base pairs. Primers used to amplify $D 7 S 2409$ were different from those in the Hispano-American families resulting in a different size of the amplified fragment. M65B was not studied in the Hispano-American families. Family CVE24 was not informative for D7S646. For families CVE17 and CVE29, the two haplotypes of the affected siblings are indicated. $N D=$ not determined. 
autosomal dominant pattern of inheritance (figure A).

Eight polymorphic microsatellite markers spanning the CCM1 interval were selected for linkage analysis. Four were chosen from the Généthon linkage map (D7S2410, D7S2409, D7S646, D7S689), and three from the Cooperative Human Linkage Center (D7S1813, D7S1789, D7S558). The last one (M65B) was identified by SL based on sequencing data of a bacterial artificial chromosome (Genbank HSAC000065; BAC RG085C05). The length of the genetic interval flanked by markers D7S2410 and D7S689 is 4 centimorgans (cM). Marker distances between D7S2410/D7S2409, D7S1813/D7S1789/D7S646/D7S558, and D7S689 have been estimated to be $2.2 \mathrm{cM}$, and $1.8 \mathrm{cM}$, respectively. ${ }^{3}$ Oligonucleotide sequences are available through the Genome Data Bank (John Hopkins University, Baltimore). Genotyping and linkage analysis (LINKAGE package version 5.1) were performed as previously described. ${ }^{5}$

Lod scores were calculated in the five families having a sufficient number of potentially informative meioses - that is, CVE3 (eight), CVE4 (16), CVE10 (seven), CVE25 (five), and CVE28 (seven). Lod scores higher than 1 were obtained for three families (CVE3, 4, and 28) for at least one marker. Due to incomplete informativity of three markers within family CVE4, lod scores did not reach the level of 3. In family CVE10, lod scores were close to 1 for four markers (D7S2410，D7S1789，D7S558，D7S689). Family CVE25 showed a lod score close to 0 for all markers. In this family, two affected and one asymptomatic sibling with norma standard MRI inherited the same haplotype from their affected father. When the data of all examined families were pooled, a maximum combined lod score of 5.92 was obtained for marker D7S2410 at $\theta=0$.

In seven families (CVE2, 3, 4, 10, 24, 25, and 28), all affected members inherited an haplotype that was not shared by their healthy relatives (figure B). In family CVE17, both affected siblings inherited a distinct haplotype from their affected mother. Although the limited size of this family does not allow to formally conclude, this suggests genetic heterogeneity. In family CVE29, the two affected siblings inherited the same haplotypes from their mother and father whose status was unknown.

None of the families shared a common haplotype (figure B). In addition, the extended Hispano-American haplotype was not segregating with the disease phenotype in any of the nine families including the four families with suggested linkage to CCM1. However, two out of nine families (CVE2 and 3), the D7S646 (185bp) and D7S558 (107bp) alleles segregating with the disease phenotype were identical to the ones observed in the Hispano-American haplotype. Consequently, we analysed the frequency of this combination of alleles within a panel of 80 haplotypes of 40 healthy white subjects. Frequency was $17 \%$ compared with $22 \%$ in our Spanish sample. Therefore, this finding might be attributed to a random distribution of these alleles.

In conclusion, linkage analysis of Spanish families with cerebral cavernous malformations did not show any evidence for HispanoAmerican haplotype sharing or a founder effect. Although our sample was limited in size and does therefore not formally exclude the presence of the Hispano-American haplotype in additional Spanish families with cerebral cavernous malformations, this haplotype is most likely not predominant in Spain, and the strong founder effect seen in all published Hispano-American families with cerebral cavernous malformations might be specific for this population.

$\mathrm{HJ}$ is supported by the Schweizerische Stiftung für medizinisch-biologische Stipendien (Switzerland), SL by the Fonds de Recherche en Santé (Canada), PL by the Collège des Enseignants de Neurologie and ZENECA pharmaceutical group. The work was founded by INSERM, Ministère de l'Enseignement Superieur et de la Recherche, CSIC, and the Fondo de Investigacion de la Seguridad Social (Fiss: 99/0407).

H H JUNG P LABAUGE S LABERGE E MARÉCHAL E TOURNIER-LASSERVE INSERM U25, Faculté de Médecine Necker, Paris, France

M LUCAS

Laboratorio de Biologia Molecular J M GARCIA-MORENO $M$ A GAMERO G IZQUIERDO

Servicio de Neurologia, Hospital Unversitario Virgen Macarena, Avenida Dr Fedriani, 41071 Sevilla, Spain

E TOURNIER-LASSERVE Hôpital Lariboisière, Paris, France

Correspondence to: E Tournier-Lasserve, INSERM U25, Faculté de Médecine Necker, 156 Rue de Vaugirard, 75730 Paris Cedex 15. France, Telephone 00331456725 97; fax 00331405601 07; email: tournier@necker.fr

1 Otten P, Pizzolato GP, Rilliet B, et al. A propos de 131 cas d'angiomes caverneux (cavernomes) du SNC, repérés par l'analyse rétrospective de 24535 autopsies. Neurochirurgie tive de 24 ; 35 ;

2 Günel M, Awad IA, Finberg K, et al. A founder mutation as a cause of cerebral cavernous malmutation as a cause of cerebral cavernous mal-
formation in hispanic Americans. N Engl f Med 1996;334:946-51.

3 Johnson EW, Lyer LM, Rich SS, et al. Refined localization of the cerebral cavernous malformation gene (CCM1) to a 4-cM interval of chromosome $7 \mathrm{q}$ contained in a well-defined YAC Contig. Genome Res 1995;5:368-80.

4 Labauge P, Laberge S, Brunereau L, et al. Hereditary cerebral cavernous angiomas: clini$\mathrm{cal}$ and genetic features in 57 French families. Lancet 1998;352:1892-7.

5 Craig HD, Günel M, Cepeda O, et al. Multilocus linkage identifies two new loci for a Mendelian form of stroke cerebral cavernous malformation, at $7 \mathrm{p} 15-13$ and $3 \mathrm{q} 25.2-27$. Hum Mol Gen 1998;7:1851-8.

Hydrocephalus caused by metastatic brain lesions: treatment by third ventriculostomy

Metastasis to the brain occurs in $20 \%-40 \%$ of cancer patients. ${ }^{1}$ About $20 \%$ of these metastases are located in the posterior fossa, cerebellum, and brainstem. Metastatic disease to periventricular brain tissue can obstruct the flow of cerebrospinal fluid (CSF) produced in the ventricles to the subarachnoid space where it is normally absorbed by arachnoid granulations. This typically causes an obstructive or non-communication hydrocephalus. A shunt has been customarily placed to drain CSF from a lateral ventricle through a pressure regulating valve and into the atrium or peritoneal or pleural cavity. Even though this technique has been successful in relieving the hydrocephalus, it has about a $50 \%$ chance of infection or failure from blockage.

Another option for the treatment of obstructive hydrocephalus is third ventriculostomy, a minimal invasive endoscopic neu- rosurgical procedure. In performing third ventriculostomy, a hole is created in the floor of the third ventricle, allowing CSF inside the ventricle to drain out to the CSF space surrounding the brain. Although third ventriculostomy has a low operative morbidity and a high probability of success in secondary hydrocephalus, it is only commonly used on patients with aqueductal stenosis and the pediatric population. To avoid placing shunts in patients with inoperable metastatic brain tumours who typically have only a few months to live, we have offered the patients third ventriculostomy as a palliative procedure.

We performed third ventriculostomy on seven patients with hydrocephalus due to metastatic tumours of the posterior fossa or thalamus. They typically presented with symptoms of acute hydrocephalus in addition to any local mass effect of the tumour. Postoperatively, five patients were relieved of hydrocephalic symptoms and follow up brain imaging studies disclosed decreased ventricular size. These five patients had a median hospital time of 6.5 days and median survival of 9.5 weeks after the operation (table). Their hospital stay was prolonged by care of their primary disease. However, most of our patients who underwent this operation for hydrocephalus caused by other diseases were discharged from the hospital between 24 and 48 hours from the procedure. There were no operative complications. All five patients had no evidence of redevelopment of hydrocephalus up to the last clinic visit.

Two patients had unsuccessful results from their third ventriculostomy. One patient (case 4) showed no change from his initial neurological exam after the procedure, but his mental status deteriorated on post operative day 6 . Brain CT showed no change in the size of his ventricles compared with the scan obtained on the day of admission. The patient's family requested comfort care only and the patient died 2 days later. In the second case (case 6) the patient had improvement in his neurological examination and ventricle size by CT scan immediately after the operation, but had recurrent symptoms of hydrocephalus 11 days later. After placement of a ventriculoperitoneal shunt, his examination returned to baseline.

Every patient except the person described in pase 4 received brain radiation therapy after the palliative procedure. One patient (case 3) underwent a course of radiation treatment prior to the operation. Another (case 5) had radiation to her orbit in the distant past after enucleation for retinoblastoma. Even though previous radiotherapy may be considered a contraindication for third ventriculostomy by some authors, it did not seem to affect the success of third ventriculostomy in our patients. Carcinomatous meningitis which could have caused a concomitant communicating hydrocephalus was not grossly evident on examination, on any of the brain imagings, or during endoscopy. However, tumours in contact with CSF space can also cause a communicating hydrocephalus by raising CSF protein which can obstruct distal CSF space and arachnoid granulations.

Our success rate of about $70 \%$ (five of seven) for third ventriculostomy in periventricular metastatic disease is consistent with the results obtained with third ventriculostomy for adult patients with secondary hydrocephalus. ${ }^{3}$ This is comparable with the alternative shunting with an implanted catheter which has a first year revision rate as high 
Table 1 Clinical characteristics of patients who underwent third ventriculostomy for obstructive hydrocephalus

\begin{tabular}{|c|c|c|c|c|c|}
\hline $\begin{array}{l}\text { Case } \\
\text { No }\end{array}$ & $\begin{array}{l}\text { Age (y), } \\
\text { Sex }\end{array}$ & Diagnosis & Result $^{\star}$ & $\begin{array}{l}\text { Postoperative stay in } \\
\text { hospital(days) }\end{array}$ & $\begin{array}{l}\text { Survival time } \\
\text { (weeks) }\end{array}$ \\
\hline 1 & $70, \mathrm{M}$ & Lung mixed adenocarcinoma and squamous cancer metastasis to thalamus & Improved & 17 & 4 \\
\hline 2 & $46, \mathrm{~F}$ & Ovarian adenocarcinoma metastases to cerebrum and medulla & Improved & 9 & 13 \\
\hline 3 & $38, \mathrm{~F}$ & Breast ductal carcinoma metastases to brainstem and cerebellum & Improved & 3 & 8 \\
\hline 4 & $75, \mathrm{M}$ & Rectal adenocarcinoma metastasis to cerebellum & Failed & 8 & 1 \\
\hline 5 & $39, \mathrm{~F}$ & Breast adenocarcinoma metastasis to cerebellum & Improved & 4 & 11 \\
\hline 6 & $60, \mathrm{M}$ & Lung adenocarcinoma metastasis to thalamus & Failed & 6 & $6+\dagger$ \\
\hline 7 & $64, M$ & Oesophageal carcinoma metastatic to cerebellum & Improved & $7+$ & $1+\dagger$ \\
\hline
\end{tabular}

${ }^{\star}$ Results are considered improved if the patient had resolution of symptoms and follow up imaging showed hydrocephalus improved or resolved. †Patient is currently alive.

as $50 \%$, with the highest failure rate in the first few months after shunt placement. ${ }^{2}$ The complication rates for both procedures are low. Third ventriculostomy and shunting can potentially cause a stroke, bleeding, ventriculitis, meningitis, a subdural haematoma, CSF leak, diabetes insipidus, and SIADH. However shunting has additional risks of mechanical malfunction, complications associated with implanting a foreign body, and overdrainage syndrome. ${ }^{4}$

Because third ventriculostomy restores near normal CSF dynamics, ${ }^{5}$ overdrainage is prevented. The procedure is also minimally invasive and safe. The procedure's low morbidity, high efficacy, and potentially short hospital stay are well suited as a palliative treatment of hydrocephalus for patients with an expected shortened life span. We propose that third ventriculostomy should be offered as a first treatment to patients suffering from obstructive hydrocephalus from unresectable tumours.

\section{TIEN T NGUYEN \\ MARK V SMITH GERARD S RODZIEWICZ \\ Department of Neurosurgery \\ SHEILA M LEMKE \\ New York, USA}

Department of Medicine, Division of Oncology, SUNY Health Science Center, University Hospital, Syracuse,

Correspondence to: Dr G S Rodziewicz, Department of Neurosurgery, 750 East Adam Street, Syracuse, NY 13210, USA. Telephone 001315464 4470;fax $\quad 001 \quad 315 \quad 464 \quad 5520$; email rodziewg@vax.cs.hscsyr.edu tous mA. Brain metastases and carcinomatous meningitis. In: Abeloff MD, Armitage JO,
Lichter AS, et al, eds. Clincal oncology. New York: Churchill Livingstone, 1995:629-41

2 Borgbjerg BM, Gjerris F, Albeck MJ, et al. Frequency and causes of shunt revision in different cerebrospinal fluid shunt types. Acta Neurochir (Wien) 1995;136:189-94.

3 Jones RFC, Kwok BCT, Stening WA, et al. The current status of endoscopic third ventriculostomy in the managment of noncommunicating hydrocephalus. Minim Invasive Neurosurg 1994;37:28-36.

4 Faulhauer K, Schmitz P. Overdrainage phenomena in shunt treated hydrocephalus. Acta Neuena in shunt treated hydroceph
rochir (Wien) 1978;45:89-101.

5 Frim DM, Goumnerova LC. Telemetric intraventricular pressure measurements after third ventriculostomy in a patient with noncommunicating hydrocephalus. Neurosurgery 1997;4: 1425-8.

Neuronal activity alters local blood flow in brain tumour adjacent to the activating cortex

Characteristics of blood flow in brain tumours have been studied extensively ${ }^{1}$; these studies are important for diagnosis of malignancy and therapy monitoring. Our study is the first to consider how activity dependent changes of regional cerebral blood flow (rCBF) alter tumour blood flow in the brain tumour adjacent to the activating cortex.

Such an interaction between cortical blood flow and tumour blood flow may be of value for evaluating mechanisms of neurological symptoms associated with brain tumours.

Neuronal activation causes an increase of regional cerebral blood flow ( $\mathrm{rCBF}$ ) in the activating cortical area. ${ }^{2}$ Near infrared spectroscopy (NIRS) demonstrates the increase in $\mathrm{rCBF}$ during neuronal activity as increases in oxygenated haemoglobin (oxy- $\mathrm{Hb}$ ) and total haemoglobin (total-Hb) with a decrease in deoxyhaemoglobin (deoxy-Hb $)^{3-5}$; NIRS is an optical method to measure concentration changes of oxy- $\mathrm{Hb}$, deoxy- $\mathrm{Hb}$, and total- $\mathrm{Hb}$ (oxy-Hb+deoxy-Hb) in cerebral vessels by means of the characteristic absorption spectra of haemoglobin in the near infrared range.

In the present study, we measured changes of oxygenation and haemodynamics in the brain tumour adjacent to the activating cortex by means of NIRS. We found transient decreases in oxy-Hb and total-Hb in the

A

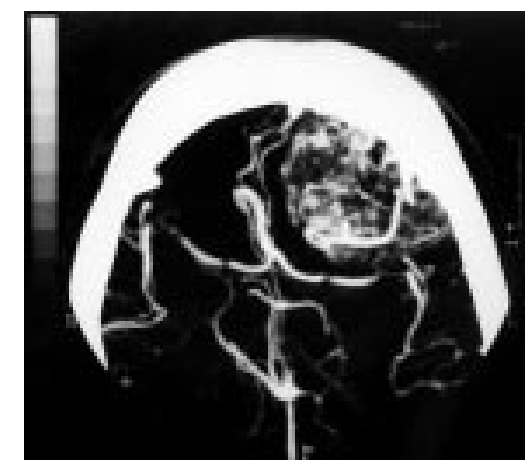

tumour during neuronal activation, suggesting that the local blood flow of the tumour was decreased by a transient increase of $\mathrm{rCBF}$ induced by neuronal activation.

The patient was a 35 year old right handed man who presented with complaints of headache and dizziness. A neurological examination showed no abnormalities and a decline in language functions. A postcontrast CT showed a well defined large enhancing tumour $(4 \times 5 \mathrm{~cm})$ compressing the left frontal lobe. Computed tomographic angiography showed that the branches of the left middle cerebral artery supplied the tumour (figure A). The patient underwent a left frontal craniotomy for removal of the tumour; the pathological diagnosis was meningioma. The NIRS measurement was performed before the operation.

We measured haemodynamic changes in the brain tumour during neuronal activation in the left frontal lobe induced by cognitive

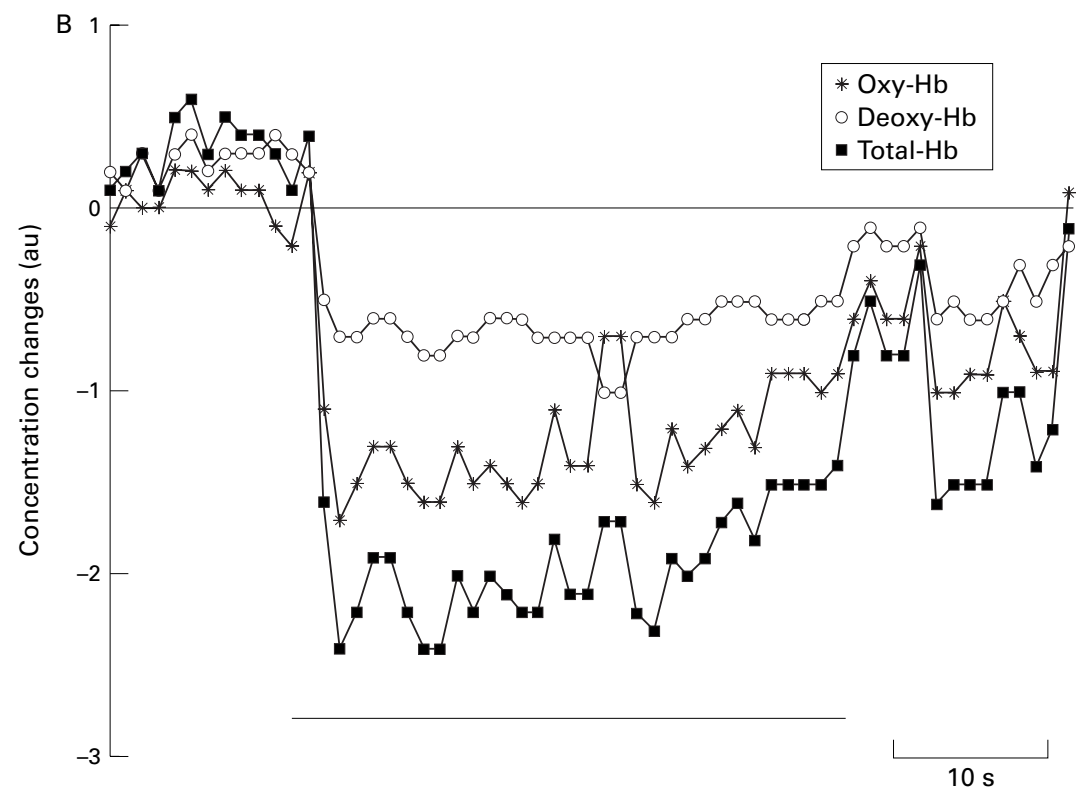

(A) CT angiography of the brain tumour. Note that the tumour was supplied by the branches of the left middle cerebral artery. (B)

Oxygenation changes in the brain tumour during the naming task measured by NIRS. The ordinates indicate concentration changes of $\mathrm{oxy}-\mathrm{Hb}$, deoxy-Hb, and total- $\mathrm{Hb}$ in arbitrary units (au). Horizontal thick bar indicates the period of the task.

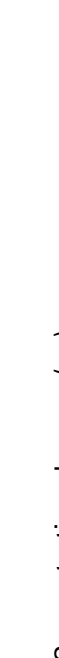


tasks. We monitored concentration changes of oxy- $\mathrm{Hb}$, deoxy-Hb, and total- $\mathrm{Hb}$, using an NIRO-500 instrument (Hamamatsu Photonics KK, Japan). The optodes were placed at an interoptode distance of $3.5 \mathrm{~cm}$ on the left forehead so that the centre of the two optodes was placed on the centre of the tumour. With an optode distance of $4 \mathrm{~cm}$, correlations of oxy-Hb and total- $\mathrm{Hb}$ measured by NIRS and rCBF measured by PET suggested that the reliable penetration depth of near infrared light into brain tissue is about $1.3 \mathrm{~cm}^{3}$; thus the present NIRS measurement area was restricted in the tumour. The patient was seated and had his eyes open during the NIRS measurement. Informed consent was obtained from the patient.

To activate the left frontal lobe, we used the following four tasks: (1) semantic verbal fluency, which entails naming as many items in a semantic category (for example, animals) as possible; (2) confrontational naming, which involves naming ordinary items presented by the tester; (3) backward digit span, a working memory task which involves reporting of digits ( 2 to 8 ) in the reverse order; (4) reading, which entails reading a short descriptive passage aloud. The speech responses of the patient to the tasks were normal.

Figure B shows an example of changes in NIRS during the naming task. After the beginning of the task, oxy- $\mathrm{Hb}$ and total- $\mathrm{Hb}$ decreased to negative values during the task, and deoxy-Hb also decreased. These changes returned to the control level gradually after the end of the task. The other tasks also caused similar changes of oxy- $\mathrm{Hb}$, total- $\mathrm{Hb}$, and deoxy-Hb.

The rCBF in the left frontal lobe is generally increased by all the tasks used in the present study. ${ }^{3-5}$ Indeed, our NIRS activation study using the cognitive tasks showed increases in oxy- $\mathrm{Hb}$ and total- $\mathrm{Hb}$ in the left frontal lobe in most normal adults-for example, increases in oxy- $\mathrm{Hb}$ and total- $\mathrm{Hb}$ were found in $92.3 \%$ of young adult subjects (mean (SD) 28.8 (4.4) years) during the word fluency task (unpublished data). Therefore, although we could not measure the changes in $\mathrm{rCBF}$ in the left frontal lobe of the patient, the evidence from our previous studies strongly suggests that the tasks caused an increase in $\mathrm{rCBF}$ in the left frontal lobe of the patient.

The decrease in oxy- $\mathrm{Hb}$ and total- $\mathrm{Hb}$ recorded from the brain tumour indicates a decrease of local blood flow in the tumour because the NIRS measurement area was restricted to the brain tumour. ${ }^{3}$ The decreases in oxy- $\mathrm{Hb}$ and total- $\mathrm{Hb}$ were found only during the tasks; consequently, these changes were probably not due to changes in systemic blood pressure, which can alter tumour blood flow. ${ }^{1}$ Based on these assumptions, we suggest that the increase of $\mathrm{rCBF}$ in the left frontal lobe induced by the tasks stole the local blood flow of the brain tumour through the cortical branches, leading to the decrease of local blood flow in the tumour.

The present report suggests that activity dependent increase in $\mathrm{rCBF}$ can steal blood flow from the adjacent tissues including nonactivating cortex. Recent NIRS activation studies have shown that cognitive tasks cause decreases in oxy- $\mathrm{Hb}$ and total- $\mathrm{Hb}$ in the left frontal lobe in some normal subjects ${ }^{4}$; these decreases indicate a decrease in rCBF. Although the physiological mechanisms of the decrease in $\mathrm{rCBF}$ during neuronal activity have not yet been elucidated, we hypothesise that a stealing of blood flow is one of the mechanisms. ${ }^{4}$ The present report supports this hypothesis.

KAORU SAKATANI HUANCONG ZUO YENG WANG

Department of Neurosurgery, China-fapan Friendship Hospital, Beijing, China

WEMARA LICHTY

Group of Detection and Analysis of Human Body Movement, Program of BME, Department of Electrical Engineering, Tsinghua University, Fapan KIYOMI YABU

Department of Rehabilitation, Takahashi Neurosurgical Hospital, Fapan

Correspondence to: Dr Kaoru Sakatani, Department of Neurosurgery, China-Japan Friendship Hospital, Yinghua East Rd., Hepingli, Beijing 100029, People's Republic of China. Telephone (fax) $0086 \quad 10$ 64203246; email sakatani@ public.east.cn.net

1 Terada T, Miyamoto K, Hyotani G, et al. Local blood flow changes in malignant brain tumors under induced hypertension. Acta Neurochir (Wien) 1992;118:108-11.

2 Fox PT, Raichle ME. Focal physiological uncoupling of cerebral blood flow and oxidauncoupling of cerebral blood flow and oxidalation in human subjects. Proc Natl Acad Sci lation in human subjects.

3 Hock C, Villringer K, Müller-Spahn F, et al. Decrease in parietal cerebral hemoglobin oxygenation during performance of a verbal fluency task in patients with Alzheimer's disease monitored by means of near-infrared spectroscopy (NIRS)-correlation with simultaneous rCBF-PET measurements. Brain Res 1997;755:293-303.

4 Sakatani K, Xie Y, Lichty W, et al. Languageactivated cerebral blood oxygenation and hemodynamic changes of the left prefrontal cortex in poststroke aphasic patients: a near cortex in poststroke aphasic patients: a near infrared 304

5 Hoshi Y, Onoe H, Watanabe Y, et al. Nonsynchronous behavior of neuronal activity, oxisynchronous behavior of neuronal activity, oxi-
dative metabolism and blood supply during dative metabolism and blood supply during
mental tasks in man. Neurosci Lett 1994;172: 129-33.

\section{Migraine aura masquerading as Balint's syndrome}

Migraine is a common neurological disorder with a prevalence of $0.5 \%$ to $2 \%$ in the general population. ${ }^{1}$ In one fourth of total migraineurs, headache is preceded by an aura. ${ }^{2}$ We describe a patient with recurrent episodes of migraine in whom headache was preceded by a constellation of visual symptomatology which constituted salient components of Balint's syndrome. This syndrome, consisting of a triad of simultagnosia, optic ataxia, and oculomotor apraxia, is seen with bilateral lesions of occipitoparietal cortices affecting connections between visual cortical regions and the frontal eye field. ${ }^{3}$

A 29 year old female teacher presented with an 8 year history of paroxysmal alternating hemicranial and throbbing headache which was often associated with nausea and photophobia. Patients fulfilled the requisite criteria for establishing the diagnosis of migraine with aura as devised by the International Headache Society (1988). ${ }^{4}$ She used to have six to eight episodes of headache a month. There was no history of status migranosus during these years. On several occasions, headache was preceded by a peculiar constellation of visual symptomatology comprising distortion of visual images followed by inability to perceive simultaneously objects in the visual field and touch an object under direct visual guidance. However, she could see the component parts of objects during the episode. These visual symptoms lasted for about 10-25 minutes and were followed by a hemicranial, throbbing headache which was often associated with nausea, photophobia, and occasionally vomiting. Headache used to last for about 4 to 18 hours and would respond to either ergot drugs or sumatriptan, especially if taken at the beginning of the episode. Occasionally these visual symptoms were not followed by headache. The patient would not lose contact with the environment during or after the visual symptoms. Her mother and two younger sisters were also having paroxysmal episodes of common migraine.

Her general physical and neurological examination in between the episodes was unremarkable. Neurological examination during the aura symptoms disclosed that she was unable to see simultaneously all the objects in the visual field (simultagnosia). She did omit several words while reading a paragraph. However, she could comprehend and read each and every word individually. On being shown a complex picture comprising multiple subunits she was not able to comprehend and perceive the entire picture but was able to perceive all the components of the picture individually (seeing in piecemeal). These aforementioned features were consistent with simultagnosia. Besides simultagnosia, she had optic ataxia as evidenced by her inability to coordinate hand and eye movements. Optic ataxia was tested as follows: each eye was tested separately and the hand ipsilateral to the eye being tested was used. The target stimulus was a $5 \mathrm{~mm}$ long pin with a white head placed at preselected locations. The patient was asked to touch this pin with her index finger without shifting her gaze from the fixation point. The patient had difficulty in performing this test but had no problems in reaching out to her own body parts or an auditory stimulus with her eyes closed. These features were consistent with optic ataxia. Moreover, gaze apraxia was evident by her inability to look at an object on command. However, she could do it spontaneously. In addition, she had impaired smooth pursuit and voluntary saccades in all directions. Reflex eye movements were normal. Visual acuity during the episode was $6 / 6$ bilaterally. Visual fields were also normal during the episode as demonstrated by the confrontation method. Ophthalmological examination, including perimetry performed during a symptom free period, was normal. There was no clinical evidence of Gerstmann syndrome, prosopognosia, object agnosia, or colour agnosia. Her cranial CT and magnetic resonance angiography were unremarkable.

Electroencephalography was also noncontributory. The frequency of visual aura symptoms and headache decreased considerably after the patient was started on flunarizine at a daily dosage of $10 \mathrm{mg}$ at bed time.

The visual impulses, after being received by the primary visual cortex (Brodmann area $17)$, are interpreted and integrated in visual association areas 18 and 19. Brodmann area 19 , in turn, is connected with the angular gyrus and frontal eye field by virtue of association fibres. Any lesion in the visual association areas or their connections would result in impaired integration of visual impulses despite normal visual acuity.

The visual symptom complex in this case possibly represents an aura of migraine. The pathogenesis of migraine aura has been a debatable issue. ${ }^{5}$ in this case it is suggested that the pathophysiological process of migraine aura results in a disconnection syndrome by 
involving visual association areas and their association pathways. Optic ataxia, gaze apraxia, and simultagnosia seem to represent a dissociation of visual information from the frontal eye field and dorsal parietal regions.

PARVAIZ A SHAH A NAFEE

Division of Neurology, Department of Medicine, Government Medical College and Associated SMHS Hospital, Srinagar, Kashmir, $\mathcal{F}$ and K 190001, India Correspondence to: Dr Parvaiz A Shah, Firdousabad, Batmaloo, Srinager, Kashmir, J and K 190001, India. Telephone 0091194452379.

1 Ziegler DK. Headache: public health problem. Neurol Clin 1990:8:781-91.

2 Campbell JK. Manifestations of migraine. Neurol Clin 1990:8:841-55.

3 Damasio AR, Tranel D. Disorders of higher brain function. In: Rosenberg RN, ed. Comprehensive neurology. New York : Raven Press, 1991:639-57.

4 Headache classification Committee or International Headache Society. Classification and diagnostic criteria for headache disorders, cranial neuralgias and facial pain. Cephalalgia 1988;3(suppl 7):1-96.

5 Blau JN. Migraine: theories of pathogenesis. Lancet 1992;339:1202-6.

"Can't you use another vaccine"? postrabies vaccination encephalitis

A healthy 39 year old man was bitten on the ankle by his own apparently normal dog. After the incident the dog disappeared into the forest and was not seen again. Three days later the patient was seen at a provincial hospital in Vietnam and started on an alternate day regimen of suckling mouse brain postrabies exposure vaccination (SMBV). After the second dose, he felt unusually lethargic although he was still able to work. After the third dose, he became unrousable, and was transferred to the Centre for Tropical Diseases, Ho Chi Minh City, the referral hospital for infectious diseases in southern Vietnam. On admission, he was afebrile, confused, had slurred speech, and his Glasgow coma score was 13. He had mild spastic weakness of his left face, left arm, and both legs. Full blood count and results from routine biochemistry and chest radiography were all normal. The CSF: blood glucose ratio was $0.47(63 / 140 \mathrm{mg} \%)$, the protein content was raised $(78 \mathrm{mg} / \mathrm{dl})$, and there was one lymphocyte/ml in the CSF. Screens for malaria toxoplasmosis, cryptococcus, and neurocysticercosis were negative, as was a CSF gram stain. The CSF was sterile after 2 weeks of culture. Brain MRI (Access Toshiba LPT $6.01 \mathrm{p}, 0.064$ Tesla) showed areas of high signal throughout the white matter, and cystic-like change in the basal ganglion and right cerebellar hemisphere (figure A). These variably sized lesions were bilateral, widely distributed, asymmetric, and showed no evidence of haemorrhage or mass effect.

As paralytic rabies could not be excluded he was managed conservatively and the SMBV course was continued. On the 4 th day after admission he deteriorated with a Glasgow coma score of 10 , and was incontinent of urine and faeces with generalised spastic paraparesis. Methylprednisolone (500 $\mathrm{mg} /$ day) was given for 5 days followed by a reducing course of prednisone for a presumptive diagnosis of postvaccination encephalitis. The SMBV was stopped. Within 72 hours of starting steroids there was a dramatic improvement in his neurological state. An MRI examination performed 4 weeks later showed a marked decrease in both size and number of brain lesions and no new lesions (figure B). After 6 weeks he was discharged talking, eat- ing, walking, and continent but with some persistent emotional liability and mild memory impairment. A follow up MRI examination 5 weeks after discharge showed further improvement, apart from minor abnormalities in the basal ganglion, and generalised increase in ventricular size, consistent with residual cerebral atrophy.

Rabies is caused by an RNA virus, a member of the Rhabdoviridae family, it infects mammals and can be transmitted to humans by contact, generally from an animal excreting the virus in the saliva. Rabies manifests as an acute encephalomyelitis, the development of which is almost invariably fatal. The distinction between rabies and postvaccine encephalitis is difficult and may be helped by antigen detection via a skin biopsy; however, this technique is not available in Vietnam. ${ }^{1}$ Paralytic rabies could not be excluded in this patient and hence steroids were not used initially. Steroids have been reported to increase mortality in experimental animals with rabies, and it has been suggested that they may abrogate the immune response to the postexposure vaccine, thus precipitating uncontrolled rabies. ${ }^{2}$

There are three types of postexposure vaccine in use world wide. The Semple type (STV) is obtained from inactivated virus prepared on adult animal nerve tissue; it is inexpensive and relatively easy to produce. In India 3 million people receive postexposure courses of STV (phenolised sheep brain) antirabies vaccine each year. ${ }^{1}$ These produce
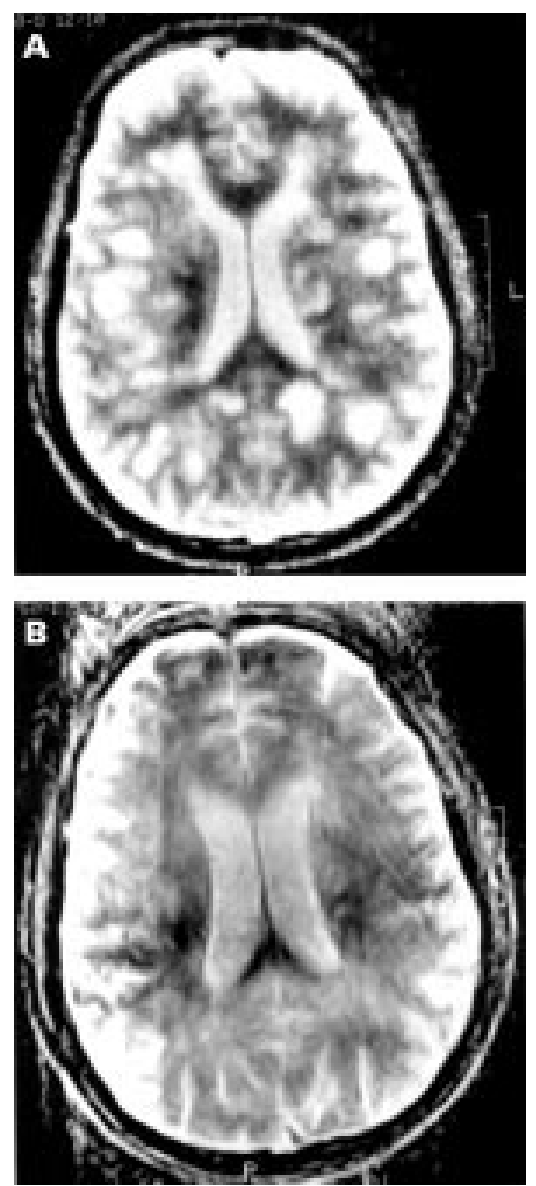

Brain MRI in May 1997. (A) T2 weighted image showing multiple areas of high signal in the cerebral white matter. Bilateral subcortical and periventricular lesions are seen. (B) Brain MRI in fuly 1997. T2 weighted image shows resolution of the white matter lesions. neurological reactions, including postvaccination encephalomyelitis, in up to 1 in 220 courses, with a $3 \%$ mortality. $^{3}$ Clinical forms include a reversible mononeuritis multiplex, and meningoencephalitic and encephalomyelitic reactions. Myelin basic protein and related neural proteins from the nervous tissue of the animal on which the virus was cultivated stimulate an autoimmune reaction in the human nervous system.

Tolerance has been improved by the development of the suckling mouse brain vaccine (SMBV). The attenuated virus is cultured on immature mouse brain tissue, which contains little myelin, thus reducing the risk of complications. SMBV is inexpensive (US\$1.5 per treatment course) and easily manufactured locally; it is the most widely used postexposure vaccine in Vietnam. Rare neurological reactions do occur with SMBV, Complications of the CNS have been reported to occur after vaccination with an incidence of 1:27000 treated people, with a $22 \%$ mortality $^{4}$ The mortality was particularly high $(90 \%)$ if there was extensive CNS involvement. The third type of vaccine available is the human diploid cell tissue culture vaccine (HDCV), which is both safe and efficacious. However, the recommended regimen is not affordable in most developing countries.

When we approached the Rabies Laboratory, Ministry of Agriculture and Fisheries, United Kingdom for advice in this case their comment was "why do you use the SMBV, can't you use another vaccine". Worldwide about 10 million people each year receive rabies vaccine after exposure; at the Centre for Tropical Diseases we treat 3000 people with dog bites annually. The cost of an HDCV in Vietnam, administered in its present regimen ( $1 \mathrm{ml}$ given for 5 days on days $0,3,7,14$, and 28 with an optional booster on day 90 ) is US $\$ 125$, making the use of this vaccine unaffordable.

This is the first report to show the demyelinating CNS lesions on MRI, and their resolution after steroid therapy. It is relatively rare for patients to survive if they develop severe CNS effects after postexposure rabies vaccination. Although the incidence of reactions to SMBV is very much lower than STV, this report confirms that it does still occur. Both SMBV and STV are widely used throughout the developing world, and would be the vaccine administered to travellers exposed to animal bites in such countries. This case stresses the need for high dose steroids in postexposure vaccine encepahlitis and the urgent need for the development and deployment of a safe, and critically, affordable postrabies exposure vaccine regimen. The economic low dose multisite intradermal regimen using the HDCV provides an example of how this goal may be achieved although it is not yet widely accepted. Such a vaccine regimen $(0.1 \mathrm{ml} \mathrm{HDCV}$ given at multisite injections on days $0,7,28$, and 90 ) could be made affordable, and offers excellent protection without the risks of postexposure immune mediated encephalitis. ${ }^{5}$

N V V CHAU T T HIEN

Centre for Tropical Diseases, 190 Ben Ham Tu, District 5, Ho Chi Minh City, Vietnam R SELLAR

Department of Clinical Neurosciences, Western General Hospital, Edinburgh, UK

R KNEEN J J FARRAR 
Wellcome Trust Clinical Research Unit, Centre for Tropical Diseases, 190 Ben Ham Tu, District 5, Ho Chi Minh City, Vietnam

R KNEEN J J FARRAR

Centre for Tropical Medicine, Nuffield Department of Clinical Medicine, fohn Radcliffe Hospital, University of Oxford, UK

Correspondence to: Dr J J Farrar, Wellcome Trust Clinical Research Unit, Centre for Tropical Diseases, 190 Ben Ham Tu, District 5, Ho Chi Minh City, Vietnam

1 Warrell MJ, Warrell DA. Rhabdoviruses: rabies and rabies related viruses. In: Weatherall DJ, Ledingham JGG, Warrell DA, eds. Oxford textLedingham JGG, Warrell DA, eds. Oxford text-
book of medicine. 3rd ed. Oxford: Oxford book of medicine. 3rd ed. Ox
University Press, 1996:394-405.

2 Fishbein DB, Bernard KW. Rabies virus. In: Mandel GL, Douglas RG, Bennett JE, eds. Principle and practice of infectious diseases. 4 th ed. New York: Churchill Livingstone, 1995:152743.

3 Swaddiwudhipong W,Prayoonwiwat N, Kunasol $\mathrm{P}$, et al. A high incidence of neurological complications following Semple anti-rabie vaccine. Southeast Asian 7 Trop Med Public Health 1987;18:526-3. 4 Toro G; Vergara I; Roman G. Neuroparalytic
accidents of antirabies vaccination with suckling mouse brain vaccine. Clinical with suckling mouse brain vaccine. Clinical and patho-
logic study of 21 cases. Arch Neurol 1977;34: logic study
$694-700$.

5 Warrell MJ, Nicholson KG, Warrell DA, et al. Economical multiple-site intradermal immuni-
sation with human diploid cell strain vaccine is sation with human diploid cell strain vaccine is
effective for post-exposure rabies prophylaxis Lancet 1985;i:1059-62.

Leukoencephalopathy associated with khat misuse

The leaves of the tree Catha edulis, or khat (also qat and kat) are chewed by a large proportion of the adult population of the Yemen, and throughout Saharan and sub-Saharan Africa. The leaves are also chewed by members of the Yemeni and Somali community in the United Kingdom. ${ }^{1}$ The psychoactive constituents of khat are cathin ( $d$ norisoephedrine), cathidine, and cathinone (an alkaloid with a structure resembling ephedrine and amphetamine) and users report a mild euphoria similar to that of amphetamine. ${ }^{1}$ Khat is acknowledged as a precipitant of psychosis and has also been reported to cause cognitive impairment. ${ }^{2} \mathrm{We}$ report a case in which khat chewing has been associated with a severe and disabling neurological illness.

A 56 year old Somali living in the United Kingdom for the past 18 years was admitted to a psychiatric hospital with a 5 week history of progressive confusion and agitation. His family reported that he had been chewing khat, in their opinion to excess, every day during that time but had stopped 2 days before admission. There was one previous admission to hospital 9 months previously with khat induced psychosis, from which he recovered without complications within 24 hours. On this occasion, shortly after admission, his conscious level deteriorated abruptly and he was referred for neurological opinion. He was apyrexial and general medical examination was normal. $\mathrm{He}$ opened his eyes spontaneously but there was no verbal response and he did not obey commands. He withdrew all four limbs to pain. Upper and lower limbs were held in flexion with markedly increased tone. Reflexes were brisk but equal. The right plantar was extensor. There were bilateral palmomental and grasp reflexes.

Full blood count, urea and electrolytes, glucose, liver function tests, thyroid function test, viral serology, and malaria screen all gave normal results. Tests for HIV antibody, serum angiotensin converting enzyme, white cell enzymes, and serum and urinary porphyrins were negative. Erythrocyte sedimentation rate on admission was $58 \mathrm{~mm} / \mathrm{h}$.

Examination of the CSF showed normal opening pressure, protein $0.27 \mathrm{~g} / 1$, glucose $4.3 \mathrm{mmol} / 1$ (blood glucose $6.1 \mathrm{mmol} / \mathrm{l}$ ), and no cells. His initial EEG was abnormal with diffuse slow waves indicative of widespread cerebral dysfunction.

A chest radiograph and ultrasound examination of the abdomen were normal. Cranial MRI, although contaminated by movement artefact, showed diffuse abnormality in the deep cerebral white matter of both cerebral hemispheres. Fourteen days after admission he was witnessed to have a single brief adversive seizure with eye and head deviation to the right.

The patient was admitted to a rehabilitation unit. His mini mental state examination score and Barthel scores were zero. Feeding by percutaneous gastrostomy was started. A trial of intravenous methylprednisolone $(1 \mathrm{~g}$ on 3 consecutive days) gave no benefit. Repeated EEGs (on four occasions) showed diffuse slow waves only. A second MRI (figure) 3 months after onset of symptom showed the presence of a continuing diffuse extensive abnormal signal in the deep white matter of both cerebral hemispheres with marked cortical atrophy. Brain biopsy (via right frontal craniotomy) was performed 3 months after the onset of his illness. There was no evidence of acute inflammation, vasculitis, or infarction.

While undergoing rehabilitation there has been slow improvement in his cognitive and locomotor function. After 1 year he is able to open and close his eyes, occasionally verbalise, localise pain, and obey simple commands. His plantars are flexor but he has persistent grasp and palmomental reflexes. His nutrition is maintained by gastrostomy and he has an indwelling catheter.

The clinical presentation, EEG, and MRI findings suggest a rapidly progressive leukoencephalopathy. There are no previous reports of leukoencephalopathy in association with khat or amphetamine misuse; it has, however, been reported in association with other recreational drugs taken by mouth or inhalation. ${ }^{34}$ An alternative for this man's

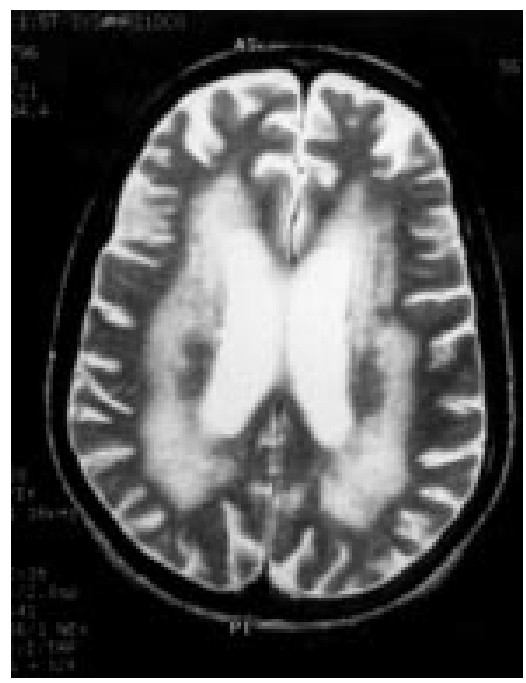

Cranial MRI 3 months after onset of symptoms showing diffuse signal abnormality in the deep white matter of both cerebral hemispheres. There is also marked cortical atrophy. presentation is a necrotising vasculitis, a well described complication of oral amphetamine misuse. ${ }^{5}$ The clinical features, MRI appearance, brain biopsy, absence of haemorrhage, and lack of response to steroids make this unlikely.

The likely precipitant of this man's illness seems to be his use of khat. A drug screen on admission was negative, and his family denied misuse of other drugs. It remains possible that the sample of khat chewed by this man was contaminated. We are unaware of any previous reports of khat misuse with severe neurological deterioration; previous cases may not have been investigated or reported. In reporting this case our intention is to alert others to a possible complication of the misuse of this drug. Evidence of other cases would provide a powerful argument for the restriction of import and sale of khat.

P K MORRISH N NICOLAOU P BRAKKENBERG P E M SMITH

Department of Neurology, University Hospital of Wales, Heath Park, Cardiff CF4 4XN, UK

Correspondence to: Dr PK Morrish, Department of Neurology, University Hospital of Wales, Heath Park, Cardiff CF4 4XN, UK. Telephone 00441222 747747 ; fax 0041222 744166; email: 747747 fax 004
morrishpk@cardiff.ac.uk

1 Pantelis C, Hindler CG, Taylor JC. Use and abuse of khat (Catha edulis): a review of the
distribution, pharmacology, side effects and a distribution, pharmacology, side effects and a
description of psychosis attributed to khat chewing. Psychol Med 1989;19:657-68.

2 Khattab NY, Galal A. Undetected neuropsychological sequelae of khat chewing in standard aviation medical examination. Aviat Space Environ Med 1995;66:739-44.

3 Celius EG, Andersson S. Leucoencephalopathy after inhalation of heroin: a case report. $\mathcal{F} \mathrm{Neu}$ rol Neurosurg Psychiatry 1996;60:694.

4 Walters EC, van Wijngaarden GK, Stam FC, et al. Leucoencephalopathy after inhaling "heroin" pyrolysate. Lancet 1982;ii:1233-7.

5 Salanova V, Taubner R. Intracerebral haemorrhage and vasculitis secondary to amphetamine
use. Postgrad Med $f$ 1984;60:429-30.

Necrotising vasculitis with conduction block in mononeuropathy multiplex with cold agglutinins

Cold agglutinins are cold reactive autoantibodies that have haemolytic effects on red blood cells mediated via complement fixation. Neuropathy associated with cold agglutinins has been described, ${ }^{1-5}$ however, details of its pathomechanism are unclear. Here, we report the clinical, electrophysiological, and pathological findings of a mononeuropathy multiplex in a patient with cold agglutinins, who responded very well to plasmapheresis.

A 72 year old man was admitted with a 1 month history of progressing dysaesthesia and weakness of the limbs. He had no anaemia, jaundice, hepatosplenomegaly, or lymphadenopathy. Cranial nerves and the cerebellum were not involved. There was severe weakness and atrophy of bilateral thenar, interossei, and plantar muscles with severe dysaesthesia of both palms and plantaris. Pin prick and light touch were reduced as well as position and vibratory sensation in both hands and feet. Deep tendon reflexes were hypoactive. Babinski's sign was negative.

Laboratory investigation showed a raised erythrocyte sedimentation rate: $52 \mathrm{~mm} /$ hour (normal $<10$ ) and serum $\mathrm{C}$ reactive protein: $1.8 \mathrm{mg} / \mathrm{dl}$ (normal; < 0.5). Blood cell counts were within normal limits. The following were normal or negative; $\operatorname{IgG}, \operatorname{IgA}, \operatorname{IgE}, \operatorname{Ig} M$, 
M-protein, direct and indirect Coombs tests, cryoglobulin, antibodies to mycoplasma, myelin associated glycoprotein, gangliosides (GM1, GD1b, asialo-GM1, GT1b, GQ1b, Gal-C), P-ANCA, and C-ANCA. The CSF was normal. Titre of cold agglutinins was detectable at $1: 1024$ at $4^{\circ} \mathrm{C}$ (normal; $<1: 256)$. The patient's serum agglutinated adult group OI-red blood cells, but not Oi-red blood cells or human cord red blood cells, signifying cold agglutinins with I specificity. Immunoelectrophoresis of the eluate confirmed IgM composition.

The initial nerve conduction study showed severe diminution or absence of compound muscle action potentials (CMAPs) with mildly diminished conduction velocities. $\mathrm{F}$ wave latencies were mildly prolonged. There were no evoked sensory nerve action potentials (SNAPs) in median, ulnar, and sural nerves bilaterally. Electromyographic studies of the affected muscles showed moderate neurogenic changes, but there were no fibrillation potentials except in the left anterior tibialis muscle. Sural nerve biopsy was performed. Epineurial vessels were surrounded by mononuclear cell infiltrates (figure A). Some vessels had focal necrosis of their wall. The small vessels in the endoneurium and epineurium showed slugging of red blood cells. The densities of large and small myelinated fibres were markedly decreased (diameter $<5 \mu \mathrm{m}: 1504 / \mathrm{mm}^{2}$, diameter $>5$

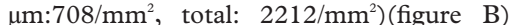
Teased fibre analysis showed that $90 \%$ of the fibres were undergoing axonal degeneration.

Oral prednisolone $(30-50 \mathrm{mg} /$ day) for 4 weeks reduced the erythrocyte sedimentation rate and $\mathrm{C}$ reactive protein, but not the serum titre of cold agglutinins; neither was there any improvement of symptoms. He received massive dose intravenous corticosteroid therapy. This moderately improved the muscle strength and sensory disturbance. Follow up nerve conduction studies (71 days after the initial study) suggested conduction block of the right median nerve on the forearm (CMAP, duration at the wrist: $2.76 \mathrm{mV}, 8.4 \mathrm{~ms}$; CMAP, duration at the elbow: $1.87 \mathrm{mV}, 8.8 \mathrm{~ms}$ ), whereas CMAP could not be elicited in the initial study. We adapted the following criteria to define conduction block: $<15 \%$ change in duration and $>20 \%$ fall in negative peak amplitude between proximal and distal sites by percutaneous supramaximal stimulation of motor nerves. As the conduction block might delay smooth recovery of symptoms, Double filtration plasmapheresis was performed four times. After the second plasmapheresis, dys- aesthesia and muscle strength improved remarkably.The titre of cold agglutinins was reduced to 1:64. The motor nerve conduction velocity (MCV) of the right median nerve likewise improved (pretreatment; $40.0 \mathrm{~m} / \mathrm{s}$, posttreatment; $57.0 \mathrm{~m} / \mathrm{s})$. Double filtration plasmapheresis was followed by oral azathioprine (50 mg/day) with tapering of steroid. He was discharged on prednisolone $(20 \mathrm{mg} /$ day $)$. In the subsequent 4 years, he has had mild exacerbation of dysaesthesia that responded to intermittent steroid therapy.

Characteristic features of the present case are as follows: (1) subacute onset of mononeuropathy multiplex; (2) necrotising vasculitis with marked loss of myelinated fibres; (3) probable conduction block in the median nerve; (4) increased concentrations of serum titres of cold agglutinin; and (5) marked response to plasmapheresis. Extensive investigation for other causes of neuropathy was negative except for an increased serum concentration of cold agglutinins, which strongly suggests that cold agglutinins may play an important part in the induction of neuropathy in this case.

Six patients with neuropathy associated with cold agglutinins have been reported ${ }^{1-5}$ including our patient. Cold agglutinins are cold reactive autoantibodies that react with the antigenic determinant termed $\mathrm{I} / \mathrm{i}$ or $\operatorname{Pr}$ present on glycoproteins and glycolipids in erythrocyte membranes. Arai et al reported a case of polyneuropathy and $\operatorname{IgM\kappa } M$ proteinemia with anti-Pr2 CA activity. IgM M protein cross reacted with sialosyl paragloboside, GT1b, GD1a, GD1b, GM3, and GD3 present in myelin and in endothelial cells of the peripheral nervous system. It has been speculated that anti-Pr2 $\operatorname{IgM}$ protein induced immune mediated damage to vascular endothelium and peripheral nervous system myelin. A similar pathomechanism has been postulated in the other cases. ${ }^{2-3}$ However, necrotising vasculitis has never been reported in neuropathy with cold agglutinins. This is the first demonstration of vasculitic neuropathy with cold agglutinins. Although the mechanism for neuropathy with cold agglutinins is unknown, mechanisms similar to those in cryoglobulinaemic neuropathy have been postulated. ${ }^{4}$ The hypotheses are (1) immunologically mediated demyelination; (2) ischaemic injury secondary to slugging or agglutination of red blood cells in the vasa nervorum; and (3) an associated vasculitis. In the present case, we have confirmed the necrotising vasculitis and probable conduction block. Pathophysiological explanations for association of vasculitis and conduction block may be as follows. Firstly, conduction block may occur as a consequence of nerve ischaemia due to small vessel occlusion. There have been reports of conduction block occurring in vasculitic neuropathy which support this possibility. Secondly, humoral factors including cold agglutinins may induce immune mediated demyelination in the peripheral nervous system. Taken together, neuropathy with cold agglutinins may involve immunologically mediated demyelination, microcirculation occlusion, and vasa nervorum vasculitis. The diversity of pathomechanisms may come from the difference target antigens recognised by cold agglutinins. Plasmapheresis proved effective in all cases. These findings strongly suggest that humoral factors including cold agglutinins may play an important part in the induction of neuropathy with cold agglutinins. We recommend plasmapheresis as first choice treatment for neuropathy associated with cold agglutinins.

We thank Dr Gerard Salazar for critical reading of the manuscript, Ms M Teshima and N Hirata for their technical assistance, Dr S Kusunoki (Department of Neurology, Institute for Brain research, University of Tokyo) for analyses of antibodies to
gangliosides, and $\mathrm{Mr} \mathrm{H}$ Moug (Division of Blood gangliosides, and Mr H Moug (Division of Blood
Transfusion Medicine, University of Kagoshima)

Transfusion Medicine, University of

R OTSUKA F UMEHARA K ARIMURA Y MARUYAMA Y ARIMURA M OSAME

The Third Department of Internal Medicine, Kagoshima University School of Medicine, Sakuragaoka 8-35-1 Kagoshima, Fapan

Correspondence to: Dr R Otsuka, The Third Department of Internal Medicine, Kagoshima University School of Medicine, Sakuragaoka 8-35-1 Kagoshima, Japan. Telephone 008199275 5332; fax $008199265 \quad 7164$; email reika@med4.kufm.kagoshima-u.ac.jp

1 Arai $\mathrm{M}$, Yoshino $\mathrm{H}$, Kusano $\mathrm{Y}$, et al. Ataxic

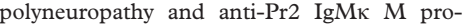
teinemia. F Neurol 1992;239:147-51.

2 Willison HJ, Paterson G, Veitch J, et al. Peripheral neuropathy assaciated with monoclonal IgM anti-Pr2 cold agglutinins. F Neurol NeuroIgM anti-Pr2 cold agglutinins. F
surg Psychiatry 1993;56:1178-83.

3 Herron B, Willison HJ, Veitch J, et al. Monoclonal IgM cold agglutinins with anti-Pr1d specificity in a patient with peripheral neuspecificity in a patient with per

4 Thomas TD, Donofrio PD, Angero J. Peripheral neuropathy in cold agglutinin disease. Muscle Nerve 1991;14:331-4.

5 Valbonesi M, Guzzini F, Zerbi D, et al. Successful plasma exchange for a patient with chronic demyelinating polyneuropathy and cold agglutinin disease due toanti-Pra. $f$ Clin Apheresis $1986 ; 3: 109-10$
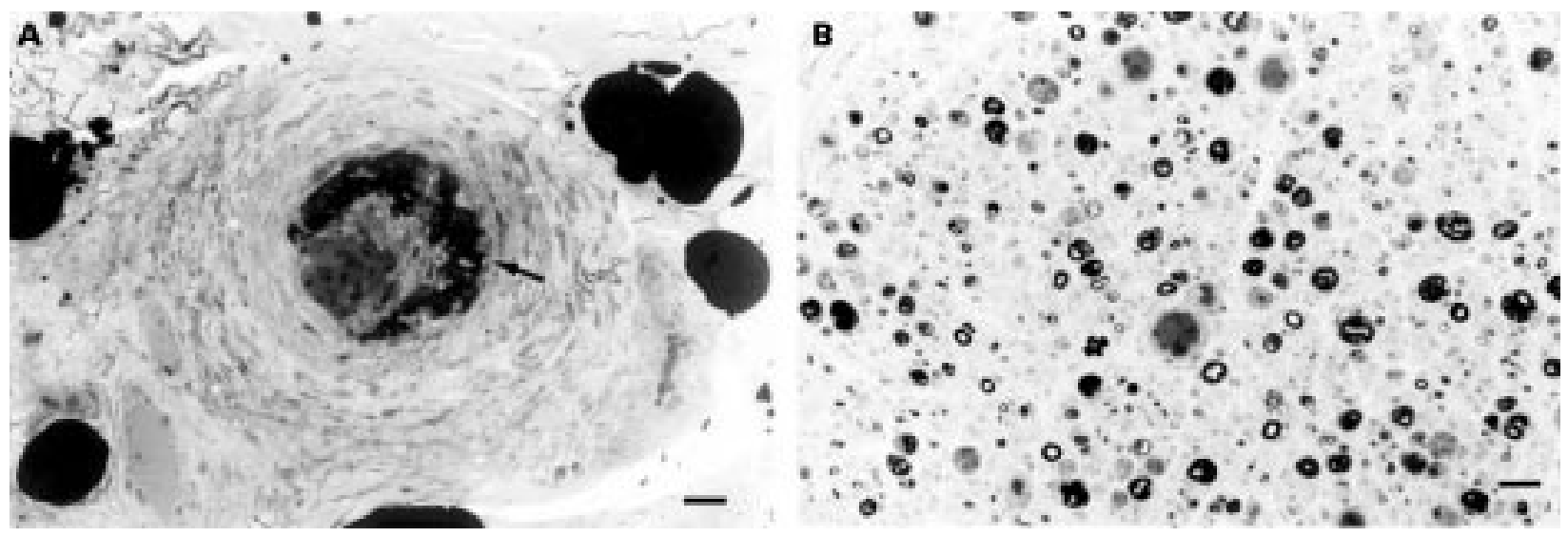

(A) Sural nerve (toluidine blue staining) showing epineurial vessel surrounded by mononuclear cell infiltrates. Note fibrin deposition (arrow) and necrosis in media. (bar $=20 \mu \mathrm{m})$. (B) Most of myelinated fibres are undergoing axonal degeneration. Many macrophages containing myelin debris infiltrate the endoneurium. (bar $=30 \mu \mathrm{m})$. 


\section{CORRESPONDENCE}

\author{
The cholinergic hypothesis of \\ Alzheimer's disease: a review of \\ progress
}

I read with interest the review of Francis et al regarding the progress of the cholinergic hypothesis of Alzheimer's disease. ${ }^{1}$ They mentioned that donepezil produced improvement or no deterioration in more than $80 \%$ of patients, and that such responses should be viewed positively considering the progressive, degenerative nature of the disease. Various donepezil manufacturer's medical representatives presenting data from a clinical study $^{2}$ also commonly use this statement. However, this only partially reveals the truth. In fact, the same study produced improvement or no deterioration in $59 \%$ patients on placebo. I think that the beneficial effect of donepezil in particular clinical trials should always be critically reviewed in comparison with placebo. In addition, as both 24 week placebo controlled donepezil trials performed so far excluded patients with behavioural disturbances, my impression is that the positive effect of donepezil on the symptoms of behavioural disturbances still remains controversial. In fact there are reports that donepezil might induce behavioural disturbances in patients with Alzheimer's disease. ${ }^{3}$ Therefore I would be extremely cautious about prescribing donepezil to patients with Alzheimer' s disease accompanied by behavioural disturbances.

Finally, donepezil was never investigated in a 30 week randomised double blind study as was mentioned in the review. The authors are probably referring to the randomised 24 week double blind placebo controlled trial with an additional 6 week single blinded placebo phase.

T BABIC

Department of Neurology, Medical School University of Zagreb, Kisaticeva 12, 10000 Zagreb, Croatia. Telephone 003851217280 , fax 003851217280 , email tomislav.babic@zg.tel.hr

1 Francis PT, Palmer AM, Snape $M$, et al. The cholinergic hypothesis of Alzheimer's disease: a review of progress. 7 Neurol Neurosurg Psychiatry 1999;66:137-47.

2 Rogers SL, Farlow MR, Doody RS, et al. A 24-week, double-blind, placebo-controlled trial of donepezil in patients with Alzheimer's disease. Donepezil Study Group. Neurology 1998;50:136-45.

3 Wengel SP, Roccaforte WH, Burke WJ, et al. Behavioural complication associated with donepezil. Am F Psychiatry 1998;155:1632-3.

4 Bouman WP, Pinner G. Violent behaviourassociated with donepezil. Am $f$ Psychiatry 1998;155:1626-7.

\section{The authors reply:}

We thank Professor Babic for the letter, which raises several interesting points. We agree that it may be more helpful to put the results attributed to treatment with donepezil in the context of the placebo response. In general, looking at this as a class effect in relation to several compounds, the picture emerging is that about twice as many people obtain a response to active treatment as to that with placebo. The high placebo response is a com- mon factor in most studies in this field and is worthy of some explanation in its own right. Although it seems that these studies compare drug treatment with that of a placebo (one treatment against no treatment), the reality is that it is a comparison of patients receiving two treatments against other patients who are receiving one form of treatment. The additional treatment regime is, of course, the care and attention that they receive by being part of the clinical study, which often seems to have an impact, not just on the patient but also on their main carer or carers.

As far as behavioural disturbances are concerned, however, our review was making the point that evidence is emerging from clinical trials to suggest that cholinomimetic drugs as a whole may have a beneficial effect on some non-cognitive behavioural symptoms. This has now been reported for at least two cholinesterase inhibitors, and two muscarinic agonists. ${ }^{1-5}$ In particular, a clear link is emerging between psychotic symptoms and cholinergic dysfunction. Thus, Bodick et $a l^{2}$ have shown that the $M_{1} / M_{4}$ agonist xanomeline causes a dose dependent reduction in hallucinations, agitation, and delusions in a 6 month randomised double blind placebo controlled, parallel group trial. In addition, Cummings and Kaufer ${ }^{6}$ have shown that the cholinesterase inhibitor tacrine is more effective in reducing psychotic features than cognitive disturbances; tacrine also reduces or abolishes hallucinations in Parkinson's disease. ${ }^{7}$ Another cholinesterase inhibitor, metrifonate, was also shown to reduce the number of hallucinations in a 26 week randomised, double blind, placebo controlled safety and efficacy study in patients with Alzheimer's disease. Further support for a link between acetylcholine and psychosis derives from postmortem data showing that the activity of choline acetyltransferase in the temporal cortex of patients with Lewy body dementia was lower in those patients with hallucinations than in patients without this feature. ${ }^{8}$ Finally, in animals the partial $\mathrm{M}_{2} / \mathrm{M}_{4}$ agonist (5R,6R)6-(3-propylthio-1,2,5thiadiazol-4-yl)-1-azabicyclo[3.2.1] octane produced a preclinical profile suggestive of antipsychotic efficacy and that the psychomimetic NMDA receptor antagonist ketamine (when administered at subanaesthetic doses) reduced brain concentrations of acetylcholine. ${ }^{10}$ Thus, on the basis of both clinical and preclinical data, a clear rationale is emerging for prescribing cholinomimetic agents for treating the non-cognitive behavioural symptoms associated with dementia, particularly psychosis.

Professor Babic is also correct in identifying two of the studies referred to as the 30 week randomised multicentre placebo controlled parallel group studies, which included a 24 week double blinded treatment phase.

We are grateful to your correspondent for providing us with the opportunity to clarify these points.

PAUL T FRANCIS

Neuroscience Research Centre, GKT School of Biomedical Science, King's College London, London SE1 9RT, UK

ALAN M PALMER MICHAEL SNAPE

Cerebrus Pharmaceuticals Ltd, Winnersh, Wokingham, RG41 5UA, UK

GORDON K WILCOCK Department of Care of the Elderly, Frenchay Hospital, Bristol, BS16 2EW, UK
1 Kaufer DI, Cummings JL, Christine D. Effect of tacrine on behavioral symptoms in Alzheimer's disease: an open laber

2 Bodick N, Offen W, Levey AI, et al. Effects of xanomeline, a selective muscarinic agonist, on cognitive function and behavioral symptoms in Alzheimer's disease. Arch Neurol 1997;54:465-73.

3 Cummings JL, Back C. The cholinergic hypothesis of neuropsychiatric symptoms in Alzheimer's disease. Am $\mathcal{f}$ Geriatr Psychiatry 1998;6:S64-78

4 Kaufer DI, Catt K, Pollock BG, et al. Donepezil in Alzheimer's disease: relative cognitive and giver distress. Neurology 1998;19(suppl 4): giver

5 Morris JC, Cyrus PA, Orazem J, et al. Metrifonate benefits cognitive, behavioral and global function in patients with Alzheimer's disease. Neurology 1998;50:1222-30.

6 Cummings JL, Kaufer D. Neuropsychiatric aspects of Alzheimer's disease: the cholinergic hypothesis revisited. Neurology 1996;47:867-83.

7 Hutchinson M, Fazzini E. Cholinesterase inhibition in Parkinson's disease. $\mathcal{F}$ Neurol Neurosurg Psychiatry 1986;61:324-5.

8 Perry EK, Marshall E, Kerwin J, et al. Evidence of a monoaminergic-cholinergic imbalance of a monoaminergic-chanergic imbalance related to visual hallucinations in Lewy
dementia. $\mathcal{F}$ Neurochem 1990;55:1454-6.

9 Bymaster FP, Shannon HE, Rasmussen K, et al. Unexpected antipsychotic-like activity with the Unexpected antipsychotic-like activity with the
muscarinic receptor ligand $(5 \mathrm{R}, 6 \mathrm{R}) 6-(3-$ muscarinic receptor ligand
propylthio-1,2,5-thiadiazol-4-yl)-1propylthio-1,2,5-thiadiazol-4-yl)-1- $1998 ; 995$ azabicyclo $179-90$.

10 Hong CH, Woo JI, Suh YH, et al. Effect of ketamine on the acetylcholine concentration of various regions of rat brain. Seoul fournal of Medicine 1987;28:347-51.

\section{BOOK REVIEWS}

Clinical Management of Diabetic Neuropathy. Edited by ARISTIDIS VEvEs. (Pp 348 , US $\$ 125)$. Published by The Humana Press, New Jersey, 1998. ISBN 0-896-03528-X.

The neuropathies of diabetes are common (as the chapters in this book repeatedly remind us) and can be very disagreeable. Symptomless neuropathy underlies foot ulceration and sepsis as the commonest clinical consequence of diabetic neuropathy but other extremely unpleasant disorders range from exceptionally severe pain to the whole range of problems resulting from autonomic failure. This book comprehensively covers every aspect of the subject, systematically (and at times exhaustively) from its epidemiology and pathogenesis (exhaustingly) to structural, functional, and clinical problems and their treatment. Most of the authors are well known in the field and their accounts are up to date and authoritiative.

Unfortunately, struggle as they might, all authorities have difficulty in defining what they mean by diabetic neuropathy and, in this regard, understanding of this complication both in clinical and pathological terms, as well as with regard to treatment, lags far behind that of the other classic diabetic complications, nephropathy and retinopathy. Even its classification presents problems and attempts to do so are found in four different chapters, describing four classifications. Repetition is an unfortunate feature of this book and-quite apart from the confusion over classification - aspects of pathogenesis, structural changes, epidemiology, diagrams, and some reference to treatment (for example, that of pain) appear repeatedly in different chapters in greater or lesser detail. 
This is certainly a book for the specialist and not at all (as the preface suggests) for the family practitioner. There are good reviews of nerve structure, causation, and treatment of painful neuropathies and focal neuropathies. The comprehensive survey of the Diabetes Control and Complications Trial (DCCT) shows in detail the only treatment which is truly effective (diabetic control); and the lengthy description of aldose reductase inhibitor trials establishes that, even after more than two decades of investigation, further trials are still needed.

Clinical evaluation of somatic and autonomic neuropathies are useful and also, to some extent, comprehensive but lack specificity - that is, normal values for simple tests are difficult to find. The huge subject of the diabetic foot is covered in these chapters and "the impact of micro and macrovascular disease" is compressed into the last nine pages of the book.

The bibliography is important and often very up to date with references ranging from 33 to 283 per chapter.

If this book is at times confusing, this reflects the confusion regarding the nature and treatment of the diabetic neuropathies as much as the overlap and repetition found in its different chapters. It is a book of reference for the specialist who will be well served by the comprehensiveness of some of its reviews and their assembly of the appropriate literature.

PETER WATKINS

Advanced Neurosurgical Navigation. By EBEN ALEXANDER III and ROBERT J MACIUNAS. (Pp 605, DM398.00). Published by Thieme, New York, 1999. ISBN 3-13-115391 1.

The quest for a means of accurate localisation of structures during neurosurgery has taxed the minds of clinicians from early in the history of the specialty, starting with Zernov's encephalometer more than a century ago. Just as the solution to the mariners' problem of determining longitude from which it partly takes its name, neuronavigation ("the surgeon's sextant") has relied on the advent of new technologies to provide solutions to an age old puzzle.

Advances In Neuronavigation begins by tracing the history of stereotaxis from a Cartesian coordinate system devised by Clarke and Horsley at the beginning of this century, through ventriculography, stereotactic brain atlases, and CT/MR frame based stereotaxis. The final part of the first section discusses the roots of image guided frameless stereotaxis through the integration of high speed graphics computers, informatics, biotechnology, and robotics.

The remainder of the text is divided into four sections. The first concerns the creation of maps from CT, MRI, MRA, PET, and various types of functional imaging. The following section discusses clinical applications of stereotaxis, beginning with different authors' experiences of their own favoured frames, the biopsy of difficult lesions such as those in the brainstem or posterior fossa, and finally experience with different image guidance systems and their integration with the operating microscope and endoscope. There then follows a series of chapters devoted to radiosurgery, and to image guidance in epilepsy and functional surgery. The final section is entitled Frontiers in Neurosurgical Navigation and considers, among other topics, intraoperative MRI, telepresence in neurosurgery, and robotics.

The incorporation of new technology is likely to alter surgical practice radically over the coming decade and equipment that seemed at the cutting edge of technology only a few years ago, such as the mechanical arm, has already passed into near obsolescence at a bewildering rate. This volume provides an excellent account of the developments which have occurred in neuronavigation, and a thought provoking insight into the wider applications of equipment of which many of us use only a fraction of the potential capability. The title of the book should perhaps have included the word cranial, as there is almost no discussion of the impact that this technology has had in surgery of the spine. This aside it is an excellent book although, like the technology it chronicles, one which is likely to date quite rapidly.

ROBERT MACFARLANE

Key Topics in Neurology. By PEM SMITH. (Pp 318, £22.95). Published by BIOS Scientific Publishers Ltd, Oxford, 1998. ISBN 1-85996-261-0.

The title and back cover of the latest addition to Neurology Lite texts contains the usual proclamations. "Concise, key topics, revision aid, essential, review"... the well trailed soundbites demanded by the consumer in the increasingly competitive market of "read less - learn more" books. This book, however, is unusual and distinct. Unlike many rivals it is not an A5 facsimile of a superior parent A3 reference tome. Brevity, so essential to the success of an overview work, has sacrificed neither clarity nor clinical relevance. The strength of Key Topics in Neurology owes much to the author's ability to negotiate skilfully the compromises necessary for a successful distillation of a large and complex field. $\mathrm{He}$ has not shied from wholesale culling of neurological ballast. The allied ability to distinguish and highlight the salient and relevant from the obscure and historical allows this small book to be surprisingly thorough in its coverage and topicality. There is sufficient up to date information on most areas of neurology such that this book would be useful for specialist registrars albeit without the detail or embellishment they seek. In terms of the aims of this book such observations must be regarded as complimentary.

My limited criticisms relate to details of layout and presentation. I found the exclusive alphabetical arrangement of chapters mildly disorientating in that, for example, History taking in Neurology is to be found at p 131. Similarly, the absence of diagrams and tables is an unexpected omission as I would imagine that this would have complemented the overall style of the book. These are minor gripes of what in print largely matches the sleeve hype and with a price tag of just $£ 27-50$ the book will be welcomed by undergraduates through to specialist registrars.

SIDDHARTHAN CHANDRAN
Readers may be interested in:

States of Mind. Edited by Roberta conlan. (Pp214, £19.99). Published by John Wiley And Sons, Chichester, 1999. ISBN 0-471-29963-4.

First Episode Psychosis. By K AITChison, KM MEEHAN, and R MURRAY. (Pp 152, £19.95). Published by Martin Dunitz, London, 1999. ISBN 1-85317-435-1.

Endoscopy in Neuro-otology. Edited By J MAGNAN and M SANNA. (Pp 101, DM198). Published by Georg Thieme Verlag, Stuttgart, 1999. ISBN 313-113061-X.

Advances in Biological Psychiatry Vol 19: New Models For Depression. Edited by D EBERT and K P EBMEIER. (Pp 204, US $\$ 170.50$ ). Published by Karger, Basel, 1998. ISBN 3-8055-6698-0.

Screening for Brain Dysfunction in Psychiatric Patients. By COOPER в HOLMES. (Pp 136, US\$36.95). Published by Charles C Thomas, Illinois, 1998. ISBN 0-39806921-2.

Management of Depression. By GIN S MALHI and PAUL K BRIDGES. (Pp 136, £19.95). Published by Martin, Dunitz Publishers, London 1998. ISBN 1-85317-547-1.

Clinical Research in Psychiatry. A Practical Guide. Edited by STEPHEN CURRAN AND CHRISTOPHER J williams. (Pp 185, £17.99). Published by Butterworth Heinemann, Oxford 1999. ISBN 07506 40731 .

\section{CORRECTION}

(a)

K Sudo, N Fujiki, S Tsuji, M Ajiki, T Higashi, M Niino, S Kikuchi, F Moriwaka, K Tashiro.

Focal (segmental) dyshidrosis in syringomyelia. f Neurol Neurosurg Psychiatry 1999;67:106-8. During the editorial process the footnote to table 1 ( $p$ 107) was wrongly transcribed.The last line- $p$ value for each pair of items: hyperhydrosis $v$ hyperhydrosis 0.0007; hypohydrosis $v$ normohydrosis 0.7282 ; normohydrosis $v$ hypohydrosis 0.0012 should read- $-\mathrm{p}$ value for each pair of items: hyperhydrosis $v$ hypohydrosis 0.0007; hyperhydrosis $v$ normohydrosis 0.7282 ; normohydrosis $v$ hypohydrosis 0.0012 . 